\title{
Vibration Signatures for Three Positive Displacement Compressors
}

David A. Yashar

W. Vance Payne

U.S. DEPARTMENT OF COMMERCE National Institute of Standards and Technology Building Environment Division Building and Fire Research Laboratory Gaithersburg, Maryland 20899-8631

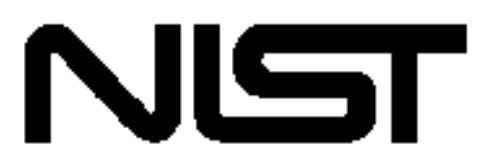

National Institute of Standards and Technology Technology Administration United States Department of Commerce 


\section{Vibration Signatures for Three Positive Displacement Compressors}

David A. Yashar W. Vance Payne

U.S. DEPARTMENT OF COMMERCE National Institute of Standards and Technology Building Environment Division Building and Fire Research Laboratory Gaithersburg, Maryland 20899-8631

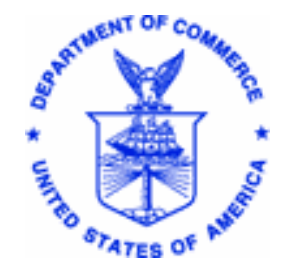

U.S. Department of Commerce Donald L. Evans, Secretary

National Institute of Standards and Technology Arden L. Bement, Jr., Director 


\title{
Vibration Signatures for Three Positive Displacement Compressors
}

\author{
David A. Yashar and W. Vance Payne
}

\begin{abstract}
This report presents vibration data for three positive displacement compressors which will be used to evaluate Microelectromechanical Systems (MEMS) vibration sensors at a later time. The axial, radial and tangential vibration signatures of three compressors were measured under different operating conditions. An open-drive four cylinder compressor's vibration signatures were measured at discharge pressures of $1724 \mathrm{kPa}(250 \mathrm{psig})$ and $2413 \mathrm{kPa}$ (350 psig), with three different drive frequencies. A hermetic scroll compressor's vibration signatures were measured at three drive frequencies with a discharge pressure of $1724 \mathrm{kPa}(250 \mathrm{psig})$, and at one drive frequency with a discharge pressure of $2241 \mathrm{kPa}$ (325 psig). Finally a large, six-cylinder, chiller compressor's vibration signatures were measured with two, four, and six of the cylinders engaged.
\end{abstract}

Keywords: compressor vibration 


\section{TABLE OF CONTENTS}

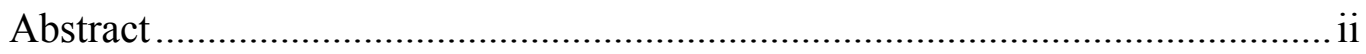

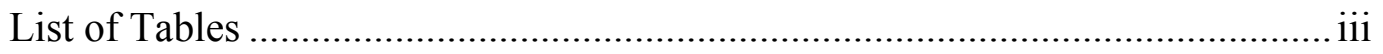

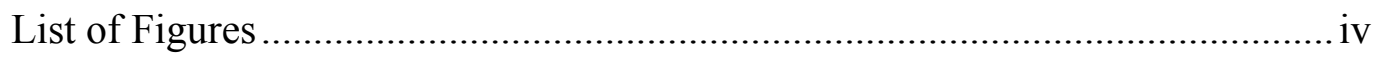

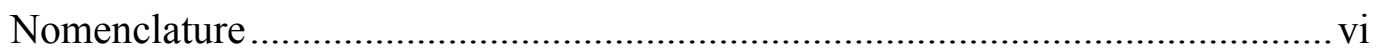

Acknowledgment ....................................................................................... vii

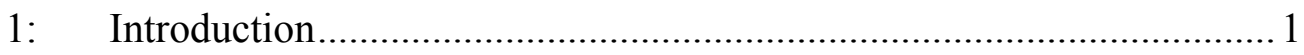

2: $\quad$ Experimental Setup ................................................................. 2

2.1: Data acquisition equipment and uncertainty................. 2

2.2: Four cylinder, reciprocating compressor ....................... 3

2.3: Hermetic, scroll compressor ......................................... 3

2.4: Six cylinder, reciprocating compressor ....................... 4

3: $\quad$ Experimental Procedure................................................................... 5

3.1: Four cylinder, reciprocating compressor test procedure 5

3.2: Hermetic, scroll compressor test procedure.................. 5

3.3: Six cylinder, reciprocating compressor test procedure... 6

4: $\quad$ Experimental Results ............................................................... 7

4.1: Four cylinder, reciprocating compressor vibration signatures ........................................................ 7

4.2: Hermetic, scroll compressor vibration signatures ......... 10

4.3: Six cylinder, reciprocating compressor vibration signatures ................................................................... 14

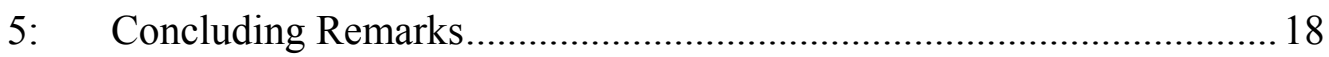

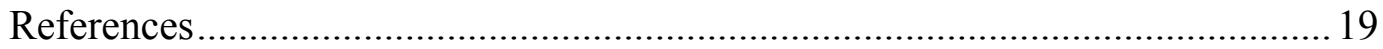

Appendix A: Vibration Analysis Derivations................................................. 20 


\section{List of Tables}

2.1.1: Data acquisition card and accelerometer specifications ........................ 2

3.1.1: Four cylinder, reciprocating compressor test conditions ........................ 5

3.2.1: Hermetic, scroll compressor test conditions ..................................... 6

3.3.1: Six cylinder, reciprocating compressor test conditions .......................... 6 


\section{List of Figures}

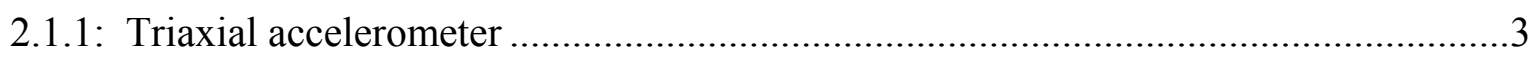

2.2.1: Four cylinder, open-drive, reciprocating compressor...............................................

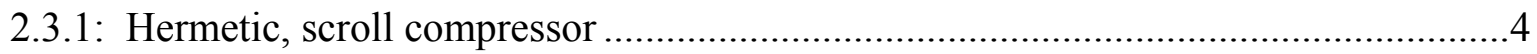

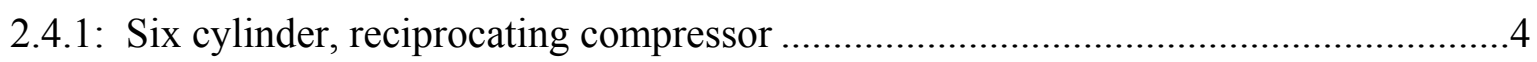

4.1.1: Axial acceleration for four-cylinder reciprocating compressor at three frequencies at the low discharge pressure.............................................................

4.1.2: Radial acceleration for four-cylinder reciprocating compressor at three frequencies at the low discharge pressure.............................................................

4.1.3: Tangential acceleration for four-cylinder reciprocating compressor at three frequencies at the low discharge pressure.......................................................

4.1.4: Axial, radial, and tangential acceleration for four-cylinder reciprocating compressor at $45 \mathrm{~Hz}$

4.1.5: Tangential acceleration for four-cylinder reciprocating compressor at three frequencies at the high discharge pressure

4.1.6: Tangential acceleration for four-cylinder reciprocating compressor at $45 \mathrm{~Hz}$ at the low and high discharge pressure

4.2.1: Axial acceleration for the scroll compressor at three frequencies at the low discharge pressure

4.2.2: Radial acceleration for the scroll compressor at three frequencies at the low discharge pressure

4.2.3: Tangential acceleration for the scroll compressor at three frequencies at the low discharge pressure

4.2.4: Axial, radial, tangential acceleration for the scroll compressor at 30 $\mathrm{Hz}$ at the low discharge pressure

4.2.5: Axial and radial acceleration for the scroll compressor at $25 \mathrm{~Hz}$ at the high discharge pressure

4.2.6: Radial acceleration for the scroll compressor at $25 \mathrm{~Hz}$ at the low and high discharge pressure. 
4.2.7: Axial acceleration for the scroll compressor failure at a drive frequency of $25 \mathrm{~Hz}$ and low pressure

4.3.1: Axial, radial, and tangential acceleration with two-cylinders loaded for the large reciprocating compressor

4.3.2: Axial, radial, and tangential acceleration with four-cylinders loaded for the large reciprocating compressor

4.3.3: Axial, radial, and tangential acceleration with six-cylinders loaded for the large reciprocating compressor.

4.3.4: Axial acceleration with two-, four-, and six-cylinders loaded for the large reciprocating compressor

4.3.5: Radial acceleration with two-, four-, and six-cylinders loaded for the large reciprocating compressor.

4.3.6: Tangential acceleration with two-, four-, and six-cylinders loaded for the large reciprocating compressor

A1: Sketch of a bearing .20 


\section{Nomenclature}

$\mathrm{f}_{\mathrm{o}} \quad$ rotational frequency of the compressor shaft $(\mathrm{r} / \mathrm{s}$ or $\mathrm{Hz})$

$\mathrm{f} / \mathrm{f}_{\mathrm{o}} \quad$ ratio of vibration frequency to the compressor shaft rotational frequency

$\mathrm{g}_{\mathrm{n}} \quad$ acceleration experienced by a unit of mass within earth's gravity field, equivalent to $9.81 \mathrm{~m} / \mathrm{s}^{2}\left(32.2 \mathrm{ft} / \mathrm{s}^{2}\right)$

OD outside diameter, $\mathrm{mm}$ (in)

RPM compressor shaft revolutions per minute

VDC volts of direct current 


\section{Acknowledgment}

The authors thank Mr. John Wamsley, Mr. Glenn Savage, and Mr. Glen Glaeser for their assistance with the testing of these compressors. 


\section{1: Introduction}

Vibration signatures of machinery contain a wealth of information regarding the interaction of all of the machine's components. For this reason, it is practicable to use vibration monitoring to detect and diagnose compressor faults before they lead to catastrophic failure. In order to successfully implement vibration as a means of fault detection, it is necessary to acquire and evaluate the appropriate measurement equipment.

Changes in the vibration signature over time may indicate that a defect has become present somewhere in the system. Therefore, it is possible to detect a fault by comparing the vibration signature of a faultless system to the signature of the same system after a period of operation. By continuously monitoring the vibration signature, it is possible to detect a fault before it becomes severe to the point of mechanical failure. Furthermore, Johnson (2000) reasoned that if a particular mode of failure were expected, one could expect to see enhanced excitation of specific frequencies while monitoring the vibration signature of a system (see Appendix A for detailed derivations regarding roller bearing failure). Therefore, it is not only possible to detect the presence of a problem, but also to diagnose problems as they arise.

Commercially available accelerometers provide an excellent means for acquiring vibration information; however the cost associated with these sensors makes them unattractive for heating, ventilation, air conditioning and refrigeration (HVAC\&R) applications. MEMS accelerometers offer a viable, low cost option for data acquisition, but they must first be evaluated for this application. In order to evaluate their feasibility, a series of vibration signatures for several compressors must be catalogued for a reference in evaluating the response of a vibration meter to known conditions. 


\section{2: Experimental Setup}

\section{1: Data acquisition equipment and uncertainty}

The vibrational signatures of each compressor were gathered using a triaxial quartz accelerometer and dynamic signal acquisition card located in the personal computer interface (PCI) bus of a personal computer. Table 2.1.1 lists the characteristics of the accelerometer and data acquisition card. Figure 2.1.1 shows the size of the triaxial accelerometer relative to a writing pen. The manufacturer of the accelerometer lists its $95 \%$ confidence limit ( two sigma on the measured value) for acceleration to be $\pm 5 \%$ of the reading. In the table below, bias level is the voltage offset above $0 \mathrm{VDC}$; therefore, all acceleration waveforms will originate (or be centered around) the bias level voltage. The bias level voltage may be subtracted from the acceleration waveform to produce the raw acceleration waveform with zero bias.

Table 2.1.1: Data acquisition card and accelerometer specifications

\begin{tabular}{|c|c|}
\hline \multicolumn{2}{|c|}{ Three-Axis Accelerometer with a $\pm 490 \mathrm{~m} / \mathrm{s}^{2}\left(50 \mathrm{~g}_{\mathrm{n}}\right)$ range } \\
\hline \hline Model & $356 \mathrm{~B} 07$ \\
\hline x-axis, sensitivity & $9.82 \mathrm{mV} /\left(\mathrm{m} / \mathrm{s}^{2}\right)\left[96.3 \mathrm{mV} / \mathrm{g}_{\mathrm{n}}\right]$ \\
\hline $\mathrm{x}$-axis, bias level & $11.6 \mathrm{VDC}$ \\
\hline y-axis, sensitivity & $10.04 \mathrm{mV} /\left(\mathrm{m} / \mathrm{s}^{2}\right)\left[98.5 \mathrm{mV} / \mathrm{g}_{\mathrm{n}}\right]$ \\
\hline y-axis, bias level & $9.69 \mathrm{mV} /\left(\mathrm{m} / \mathrm{s}^{2}\right)\left[95.0 \mathrm{mV} / \mathrm{g}_{\mathrm{n}}\right]$ \\
\hline z-axis, sensitivity & $11.3 \mathrm{VDC}$ \\
\hline z-axis, bias level & 2 analog, $16 \mathrm{bit}$ \\
\hline \multicolumn{2}{|c|}{ PCI Dynamic Signal } \\
\hline Sample Rate & 5 to 205 thousition Card \\
\hline Inputs & $0 \mathrm{kHz}$ to $95 \mathrm{kHz}$ \\
\hline Bandwidth & $90 \mathrm{~dB}$ \\
\hline Dynamic Range &
\end{tabular}




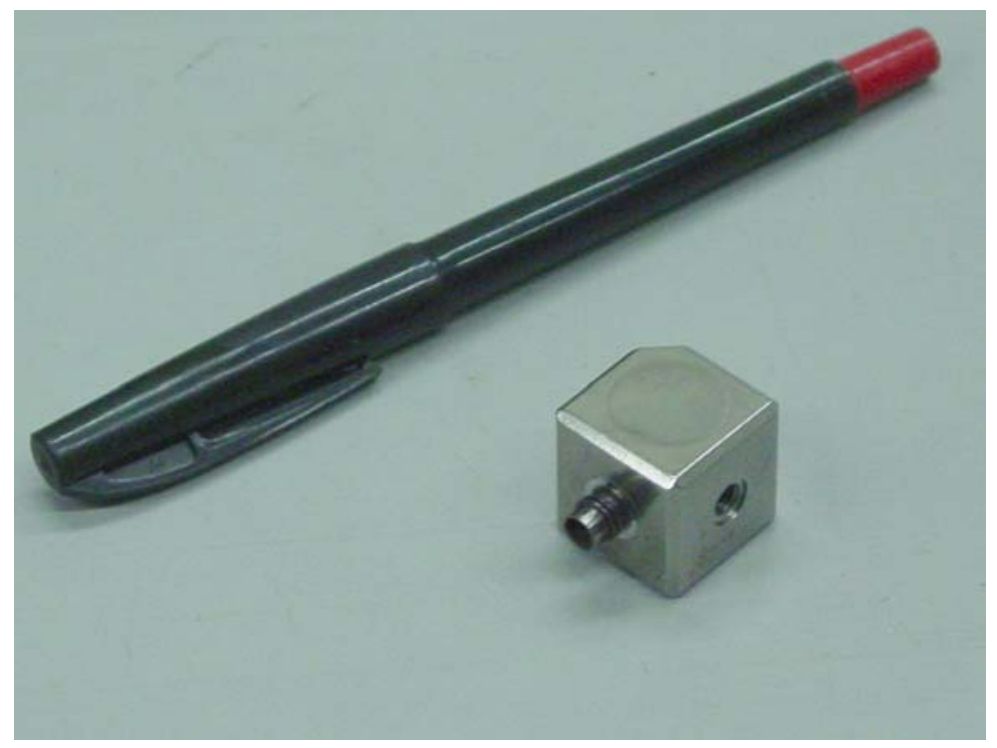

Figure 2.1.1: Triaxial accelerometer

Data acquisition code was written using commercial DAQ software. The vibrational waveforms were captured and analyzed using a Fast Fourier Transform (FFT) to clarify those frequencies experiencing the high amplitude vibration.

\section{2: Four cylinder, reciprocating compressor}

The open-drive R22 compressor shown in Figure 2.2.1 was connected to a $5.6 \mathrm{~kW}(7.5 \mathrm{hp})$ motor with full speed of $184.3 \mathrm{rad} / \mathrm{s}(1760 \mathrm{RPM})$ at $60 \mathrm{~Hz}$. This compressor uses bronze bushed bearings. The picture on the right-hand side of Figure 2.2.1 uses arrows to indicate where the mounting fixtures for the accelerometer were located. Radial, axial, and tangential vibration measurements were taken for this compressor.
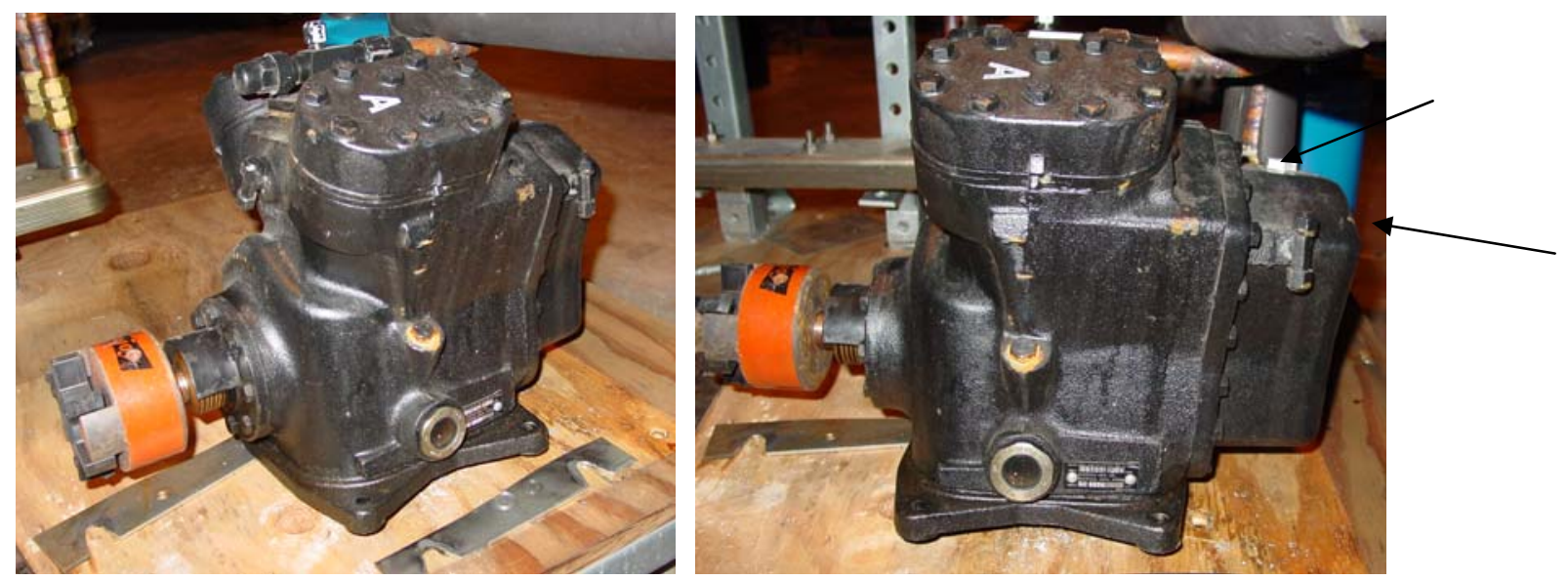

Figure 2.2.1: Four cylinder, open-drive, reciprocating compressor (the arrows on picture at the right indicate the position of vibration sensor mounts)

\section{3: Hermetic, scroll compressor}

The R410A scroll compressor shown in Figure 2.3.1 had a displacement of $10.13 \mathrm{~m}^{3} / \mathrm{h}$ $\left(5.96 \mathrm{ft}^{3} / \mathrm{min}\right)$ at $366.5 \mathrm{rad} / \mathrm{s}(3500 \mathrm{RPM})$ operating at $230 \mathrm{~V}, 3$-phase. Figure 2.3.1 uses arrows 
to indicate where the mounting fixtures for the accelerometer were located. Radial, axial, and tangential vibration measurements were taken for this compressor.

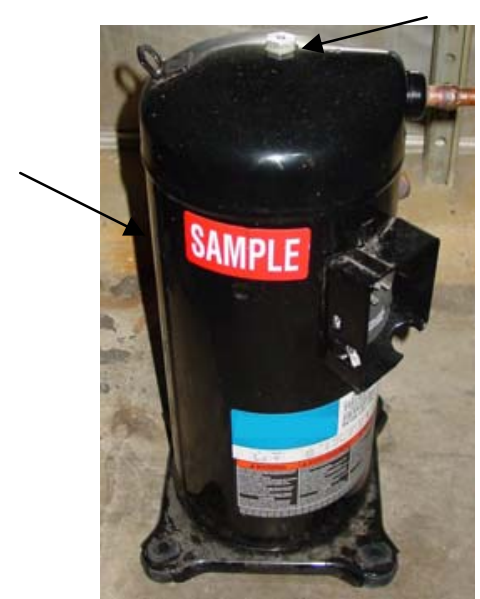

Figure 2.3.1: Hermetic, scroll compressor (the arrows on the picture indicate the position of the vibration sensor mounts)

\section{4: Six cylinder, reciprocating compressor}

The large, open-drive R404A compressor shown in Figure 2.4 .1 has a displacement of $796 \mathrm{~m}^{3} / \mathrm{h}$ $\left(7.54 \mathrm{ft}^{3} / \mathrm{s}\right)$. The compressor can be operated with two, four, or six cylinders with various amount of hot-gas bypass for capacity control. The unit operates at constant shaft rotational speed. Motor shaft speed is $186.9 \mathrm{rad} / \mathrm{s}$ (1785 RPM) on a $26.0 \mathrm{~cm}$ OD (10.25 in OD) sheave connected to the driven sheave with an OD of $67.3 \mathrm{~cm}(26.5 \mathrm{in})$. This produces a compressor shaft rotational speed of approximately $72.3 \mathrm{rad} / \mathrm{s}(690 \mathrm{RPM})$. The compressor uses automotive style journal bearings fed by pressurized oil on its crankshaft. Figure 2.4.1 uses arrows to indicate where the mounting fixtures for the accelerometer were located. Radial, axial, and tangential vibration measurements were taken for this compressor.
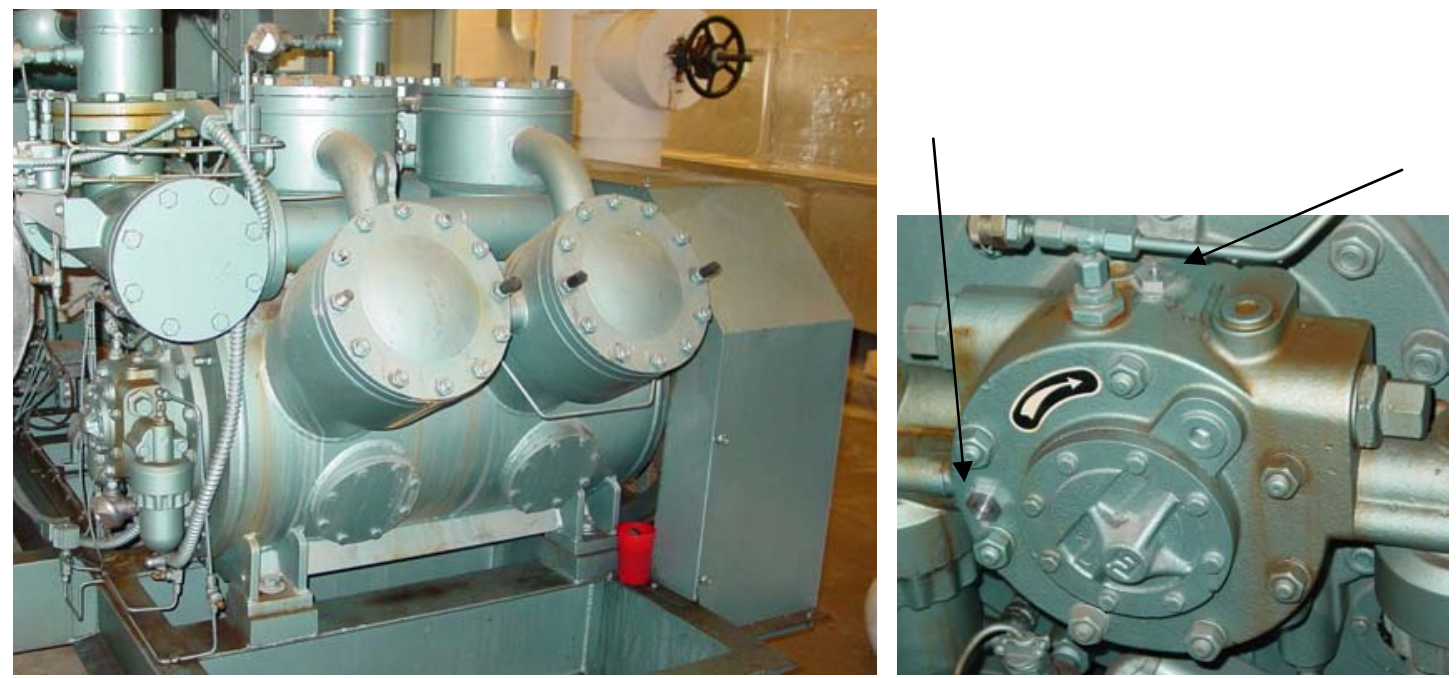

Figure 2.4.1: Six cylinder, reciprocating compressor (the arrows on the picture at the right indicate the position of the vibration sensor mounts) 


\section{3: Experimental Procedure}

A triaxial accelerometer was mounted on each compressor in two locations; 1) close to the main axis of the compressor crank shaft for axial and radial acceleration measurements, and 2) tangential to the crank-axis for tangential acceleration measurements. Several scans were made at a rate of 100000 scans per second for $1 \mathrm{~s}$ in the axial, radial, and tangential directions. Data were recorded as voltages with respect to sample time, and the data were also processed using FFT to reveal frequency characteristics of the vibration signals.

To further aid in simplifying the data, the vibration frequencies were tabulated as multiples of the rotational frequency $\left(r / s, f_{0}\right)$. Estimates of the rotational frequency for the four cylinder reciprocating compressor and the hermetic scroll compressor were based upon the drive frequency and the motor speed at $60 \mathrm{~Hz}$. A simple linear relationship was assumed to give an estimate of the rotational frequency, i.e., Drive frequency / $60 \mathrm{~Hz} x$ Motor Rotational Velocity at $60 \mathrm{~Hz}$. The estimated rotational frequency of the six cylinder reciprocating compressor was $72.3 \mathrm{rad} / \mathrm{s}(690 \mathrm{RPM})$.

In all cases, the peaks of the various harmonics were typically within $2 \%$ of the estimated rotational frequency, with the most extreme difference being less than $9 \%$. The exact rotational frequency was found by adjusting the frequency so that the harmonics aligned with integer multiples of the rotational frequency.

\section{1: Four cylinder, reciprocating compressor test procedure}

The compressor was tested with two discharge pressures and three different drive frequencies. Table 3.1.1 lists the pressures, drive frequencies, and resulting shaft rotational frequency for each test.

Table 3.1.1: Four cylinder, reciprocating compressor test conditions

\begin{tabular}{|c|c|c|c|}
\hline \multirow{2}{*}{ Drive Frequency } & \multirow{2}{*}{$\begin{array}{c}\text { Estimated Shaft } \\
\text { Rotational Speed }\end{array}$} & \multicolumn{2}{|c|}{ True Shaft Rotational Speed } \\
\cline { 3 - 4 } & & $1724 \mathrm{kPa}(250 \mathrm{psig})$ discharge & $2413 \mathrm{kPa}(350 \mathrm{psig})$ discharge \\
\hline $25 \mathrm{~Hz}$ & $76.8 \mathrm{rad} / \mathrm{s}$ & $72.3 \mathrm{rad} / \mathrm{s}$ & $70.7 \mathrm{rad} / \mathrm{s}$ \\
& $(733 \mathrm{RPM})$ & $(690 \mathrm{RPM})$ & $(675 \mathrm{RPM})$ \\
\hline $35 \mathrm{~Hz}$ & $107.4 \mathrm{rad} / \mathrm{s}$ & $104.7 \mathrm{rad} / \mathrm{s}$ & $103.7 \mathrm{rad} / \mathrm{s}$ \\
& $(1026 \mathrm{RPM})$ & $(1000 \mathrm{RPM})$ & $(990 \mathrm{RPM})$ \\
\hline $45 \mathrm{~Hz}$ & $138.2 \mathrm{rad} / \mathrm{s}$ & $136.7 \mathrm{rad} / \mathrm{s}$ & $136.1 \mathrm{rad} / \mathrm{s}$ \\
& $(1320 \mathrm{RPM})$ & $(1305 \mathrm{RPM})$ & $(1300 \mathrm{RPM})$ \\
\hline
\end{tabular}

\section{2: Hermetic, scroll compressor test procedure}

The scroll compressor had been part of an R410A variable speed condensing unit. Before the vibration tests, the scroll was operated between $40 \mathrm{~Hz}$ and $65 \mathrm{~Hz}$ during the system testing and at various operating conditions with the added protection of an oil separator on the compressor discharge. The compressor performed with almost no audible noise or vibration for several weeks while operating in the normal frequency range. The operator then began to notice the amperage draw of the compressor had increased over a several day period. This change in amperage caused him to observe the compressor more closely. During a normal test where the 
condensing unit compressor was operating at $45 \mathrm{~Hz}$, a loud rattle was heard and the compressor over-amped, tripping the amperage limit on the variable speed drive. Subsequent attempts to operate the compressor above a $40 \mathrm{~Hz}$ drive frequency resulted in the same loud rattle and shutdown after less than 3 min of operation.

In order to obtain some useful vibration data from this compressor, the compressor drive frequency was lowered until the compressor would operate for $10 \mathrm{~min}$ to $15 \mathrm{~min}$ without rattle or over-amping. Vibration data were recorded at two pressures and several drive frequencies below the rattling frequency. At higher pressures the compressor exhibited excessive noise and vibration due to an unknown failure of its internal components. The loud knock and excessive vibration data were also recorded and presented in this report. Table 3.2.1 shows the test matrix for this compressor. Tests at higher frequencies were not possible due to excessive vibrations and motor over-amping (high current draw).

Table 3.2.1: Hermetic, scroll compressor test conditions

\begin{tabular}{|c|c|c|c|}
\hline Drive Frequency & \multirow{2}{*}{$\begin{array}{c}\text { Estimated Shaft } \\
\text { Rotational Speed }\end{array}$} & \multicolumn{2}{|c|}{ True Shaft Rotational Speed } \\
\cline { 3 - 4 } & & $1724 \mathrm{kPa}(250 \mathrm{psig})$ discharge & $2413 \mathrm{kPa}(350 \mathrm{psig})$ discharge \\
\hline $20 \mathrm{~Hz}$ & $122.2 \mathrm{rad} / \mathrm{s}$ & $119.4 \mathrm{rad} / \mathrm{s}$ & \\
& $(1167 \mathrm{RPM})$ & $(1140 \mathrm{RPM})$ & $141.4 \mathrm{rad} / \mathrm{s}$ \\
& $152.7 \mathrm{rad} / \mathrm{s}$ & $150.8 \mathrm{rad} / \mathrm{s}$ & $(1350 \mathrm{RPM})$ \\
\hline $25 \mathrm{~Hz}$ & $(1458 \mathrm{RPM})$ & $(1440 \mathrm{RPM})$ & \\
& $183.3 \mathrm{rad} / \mathrm{s}$ & $183.3 \mathrm{rad} / \mathrm{s}$ & \\
\hline $30 \mathrm{~Hz}$ & $(1750 \mathrm{RPM})$ & $(1750 \mathrm{RPM})$ & \\
&
\end{tabular}

\section{3: Six cylinder, reciprocating compressor test procedure}

The large, open-drive reciprocating compressor was tested with different numbers of cylinder engaged. Pressure control and drive frequency control were not possible with this compressor. Table 3.3.1 lists the test matrix for this compressor.

Table 3.3.1: Six cylinder, reciprocating compressor test conditions

\begin{tabular}{|c|c|c|c|}
\hline & \multicolumn{3}{|c|}{ True Shaft Rotational Speed } \\
\hline $\begin{array}{c}\text { Estimated Drive } \\
\text { RPM }\end{array}$ & $\begin{array}{c}2 \text { cylinders (with hot gas } \\
\text { bypass })\end{array}$ & 4 cylinders & 6 cylinders \\
\hline $72.3 \mathrm{rad} / \mathrm{s}$ & $71.9 \mathrm{rad} / \mathrm{s}$ & $71.6 \mathrm{rad} / \mathrm{s}$ & $71.0 \mathrm{rad} / \mathrm{s}$ \\
$(690 \mathrm{RPM})$ & $(687 \mathrm{RPM})$ & $(684 \mathrm{RPM})$ & $(678 \mathrm{RPM})$ \\
\hline
\end{tabular}




\section{4: Experimental Results}

The following figures characterize the vibrational signatures of the three compressors operating under various load conditions.

\section{1: Four cylinder, reciprocating compressor vibration signatures}

This compressor was operated at two different discharge pressures and three drive frequencies. Figures 4.1.1, 4.1.2, and 4.1.3 show the axial, radial, and tangential components, respectively, of acceleration at multiples of the rotational speed for $1724 \mathrm{kPa}(250 \mathrm{psig})$ discharge pressure and three different drive speeds. Figure 4.1.4 shows the axial, radial, and tangential vibration signatures at a $1724 \mathrm{kPa}(250 \mathrm{psig})$ discharge pressure with a drive frequency of $45 \mathrm{~Hz}$. Figure 4.1.5 shows the tangential acceleration for $2413 \mathrm{kPa}(350 \mathrm{psig})$ discharge pressure at drive frequencies of $25 \mathrm{~Hz}, 35 \mathrm{~Hz}$, and $45 \mathrm{~Hz}$. Figure 4.1.6 shows the tangential acceleration at a drive frequency of $45 \mathrm{~Hz}$ for both discharge pressures.

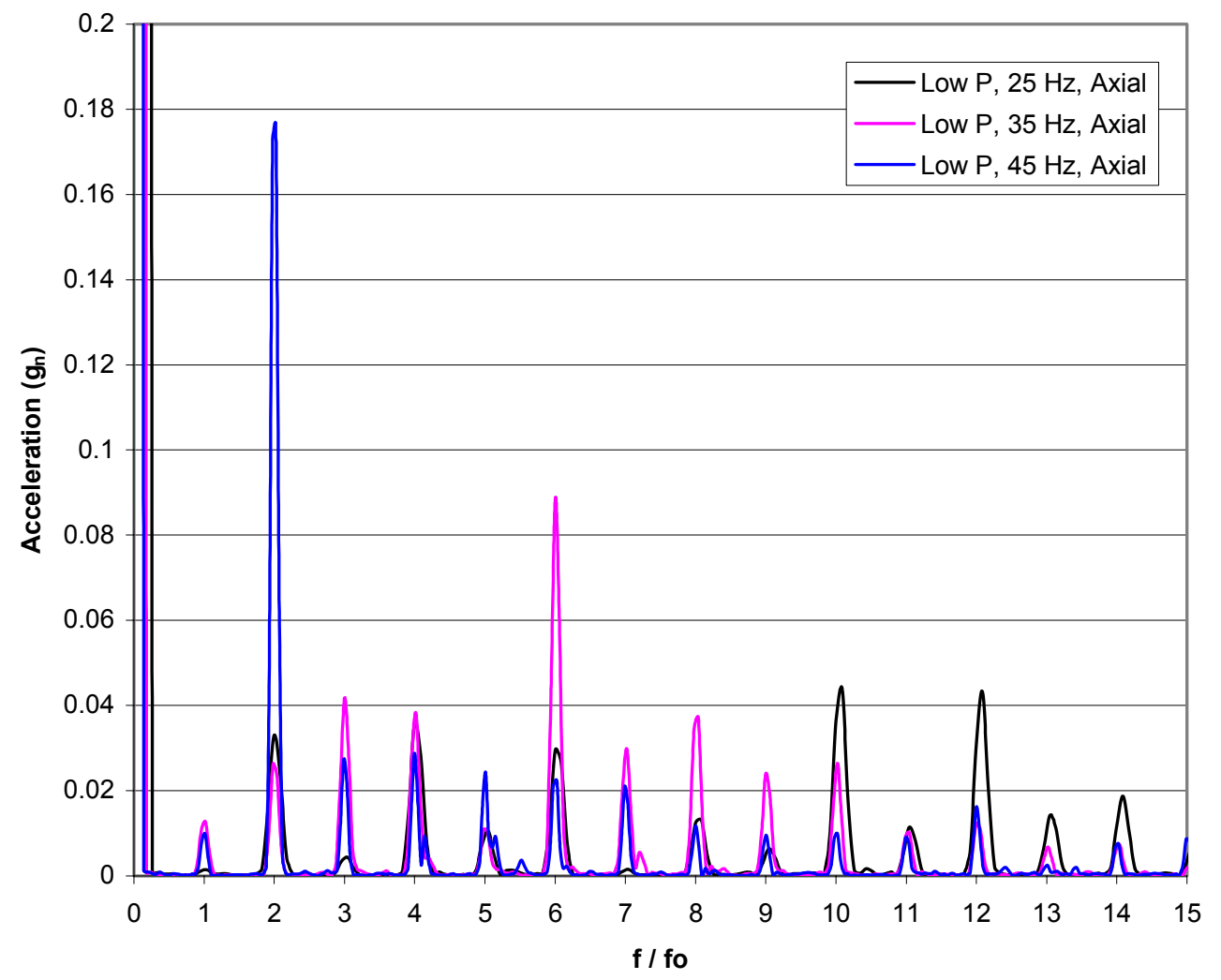

Figure 4.1.1: Axial acceleration for four-cylinder reciprocating compressor at three frequencies at the low discharge pressure 


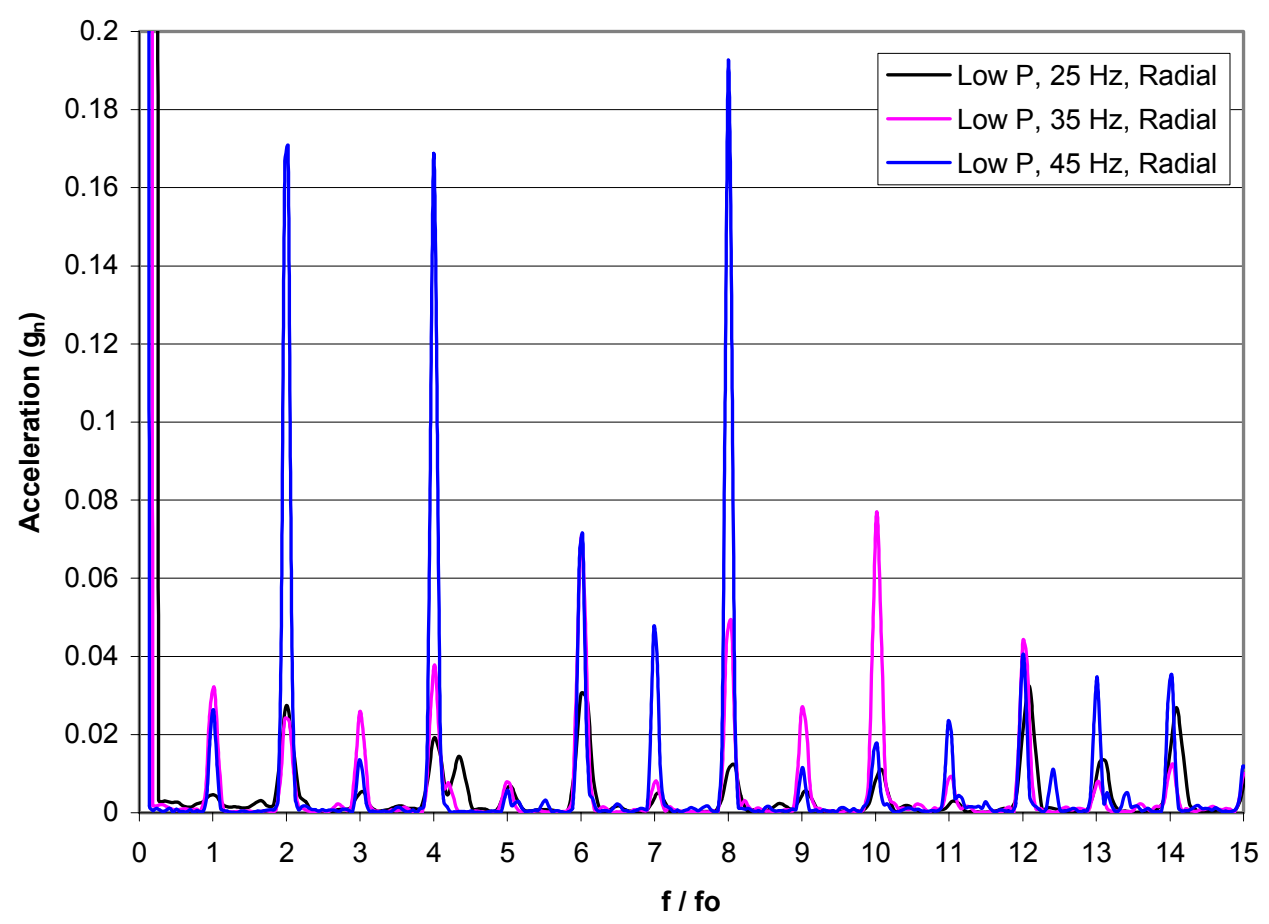

Figure 4.1.2: Radial acceleration for four-cylinder reciprocating compressor at three frequencies at the low discharge pressure

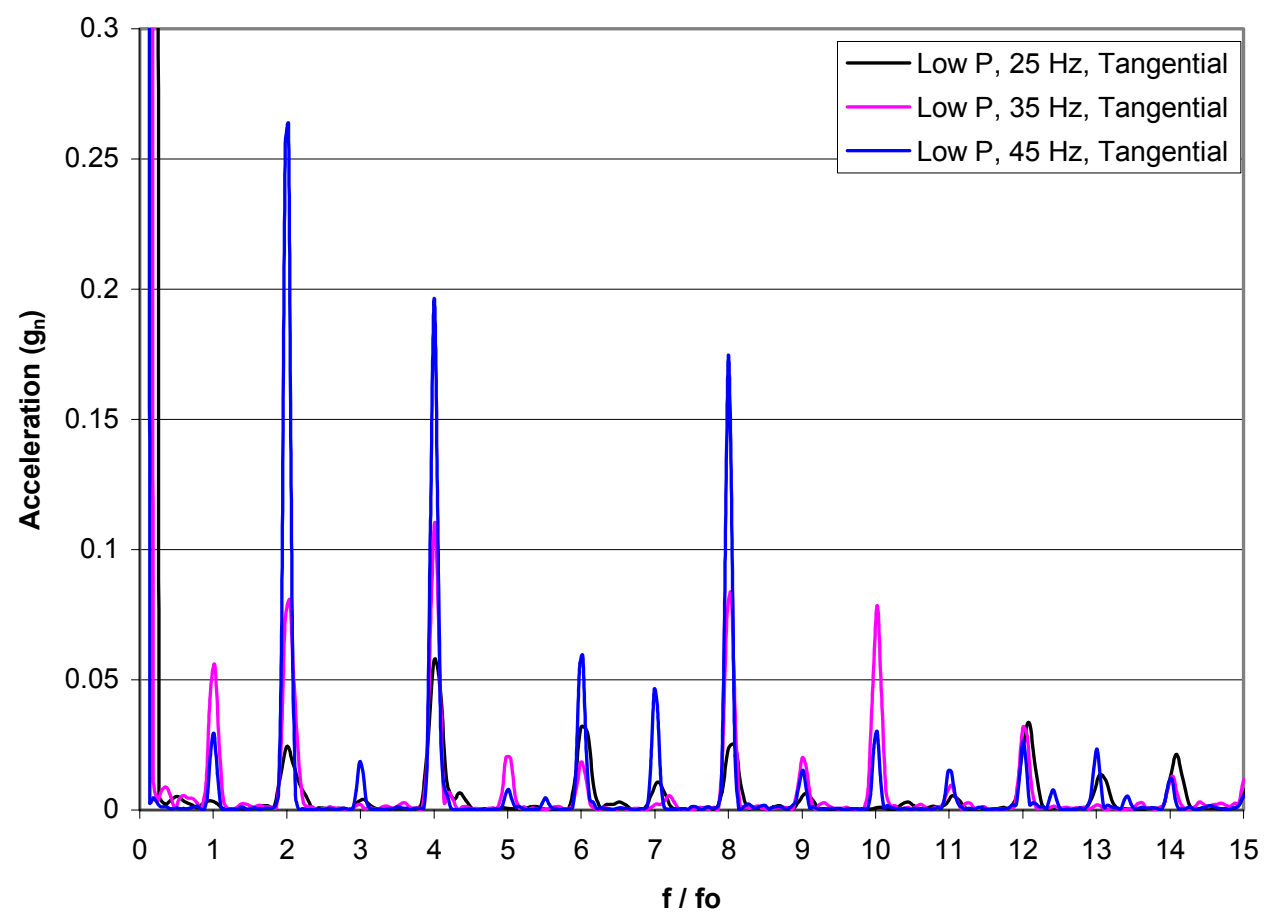

Figure 4.1.3: Tangential acceleration for four-cylinder reciprocating compressor at three frequencies at the low discharge pressure 


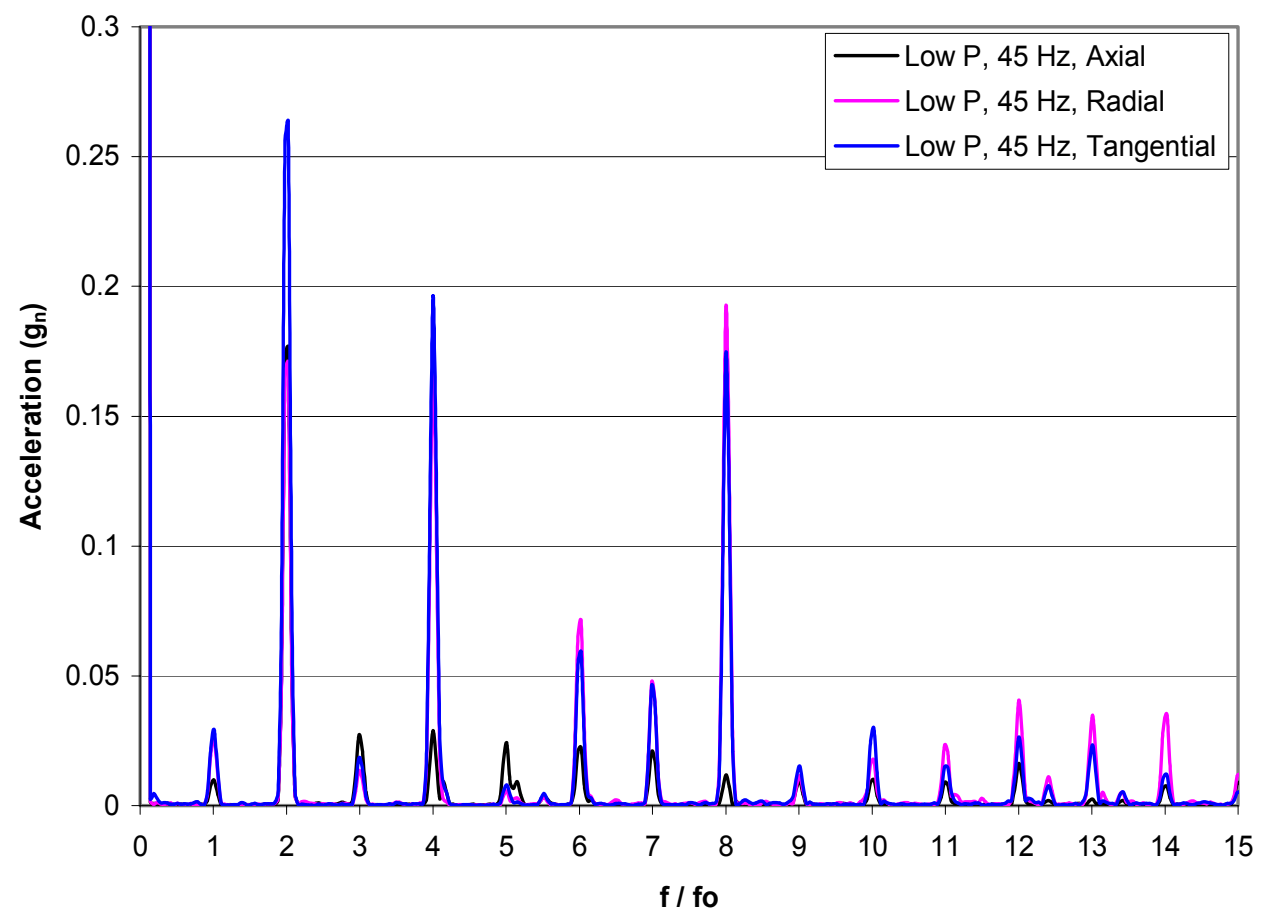

Figure 4.1.4: Axial, radial, and tangential acceleration for four-cylinder reciprocating compressor at $45 \mathrm{~Hz}$

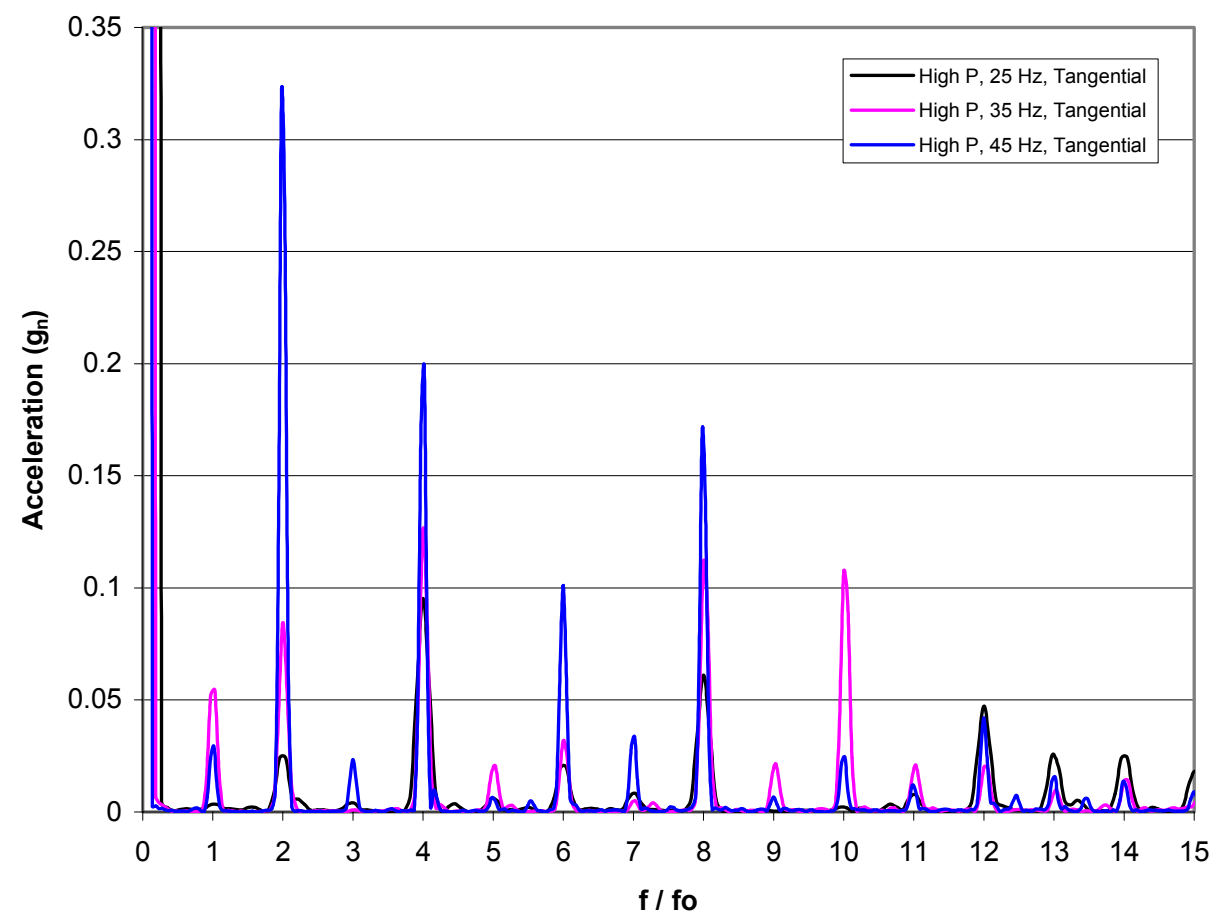

Figure 4.1.5: Tangential acceleration for four-cylinder reciprocating compressor at three frequencies at the high discharge pressure 


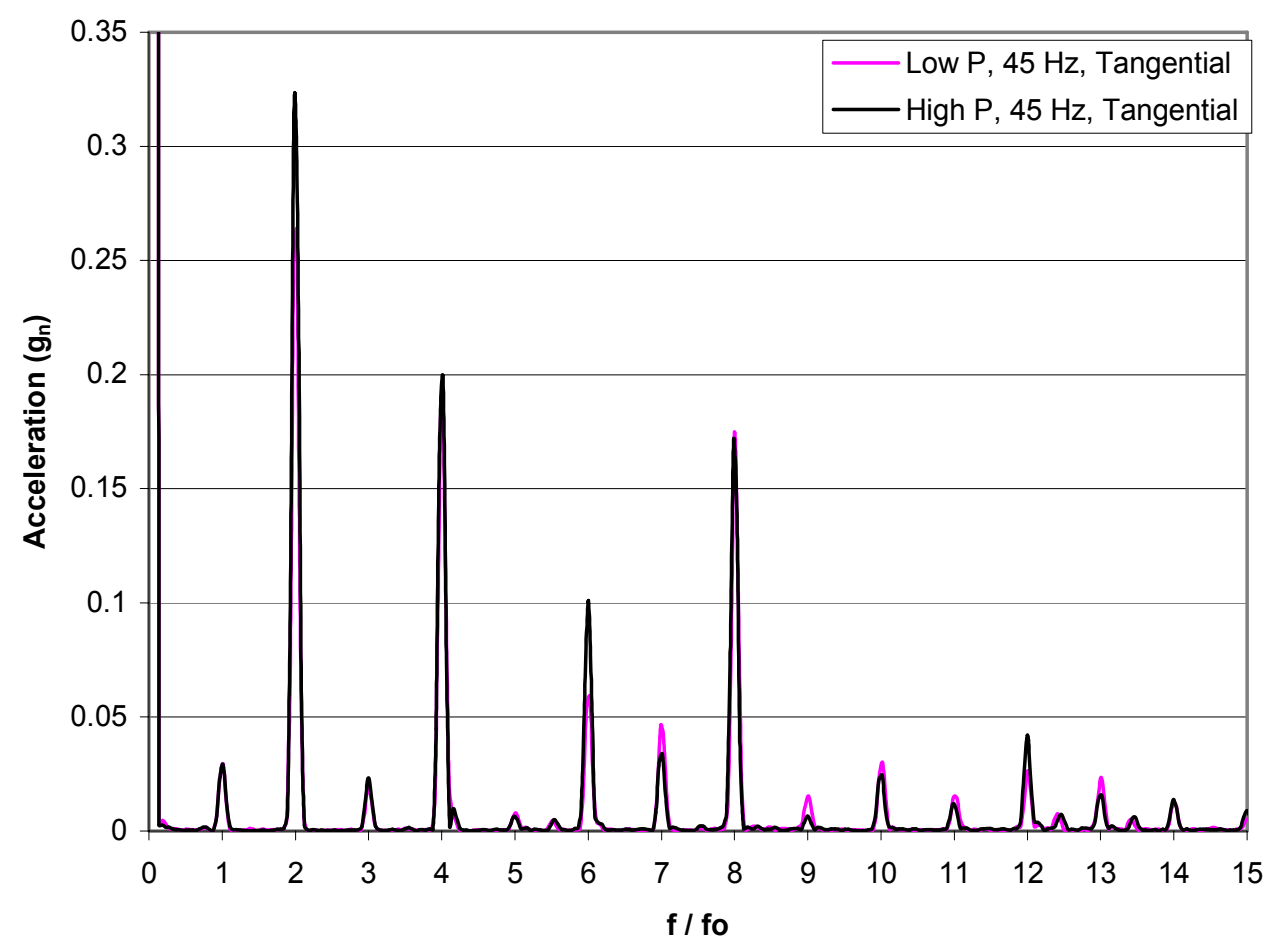

Figure 4.1.6: Tangential acceleration for four-cylinder reciprocating compressor at $45 \mathrm{~Hz}$ at the low and high discharge pressure

\section{2: Hermetic, scroll compressor vibration signatures}

The scroll compressor was tested at $20 \mathrm{~Hz}, 25 \mathrm{~Hz}$, and $30 \mathrm{~Hz}$ with a discharge pressure of $1724 \mathrm{kPa}$ (250 psig). The compressor was tested at $25 \mathrm{~Hz}$ and $2241 \mathrm{kPa}(325 \mathrm{psig})$ as well, but only axial and radial acceleration were measured. Only one frequency was tested at the higher pressure due to excessive noise and over-amping of the variable speed drive. The figures below show the vibration amplitude with frequencies shown as multiples of the rotational frequency.

Figures 4.2.1, 4.2.2, and 4.2.3 show the axial, radial, and tangential components, respectively, of acceleration at multiples of the rotational speed for $1724 \mathrm{kPa}(250 \mathrm{psig})$ discharge pressure and three different drive speeds. Figure 4.2.4 shows the axial, radial, and tangential vibration signatures at a $1724 \mathrm{kPa}(250 \mathrm{psig})$ discharge pressure with a drive frequency of $30 \mathrm{~Hz}$. Figure 4.2.5 shows the axial and radial acceleration for $2241 \mathrm{kPa}(325 \mathrm{psig})$ discharge pressure at a drive frequency of $25 \mathrm{~Hz}$. Figure 4.2.6 shows the radial acceleration at a drive frequency of $25 \mathrm{~Hz}$ for both discharge pressures.

Figure 4.2.7 shows the vibrations experienced by the scroll compressor during a failure. The system was immediately shut down by the technician when these vibrations occurred. The figure shows that acceleration in the axial direction approached $3 \mathrm{~g}_{\mathrm{n}}$ 's at a frequency ratio between 0.03 and 0.05 . This corresponds to approximately $8 \mathrm{~Hz}$ to $10 \mathrm{~Hz}$ in the frequency domain. This level of vibration is two to three orders of magnitude larger than vibrations seen during normal operation. 


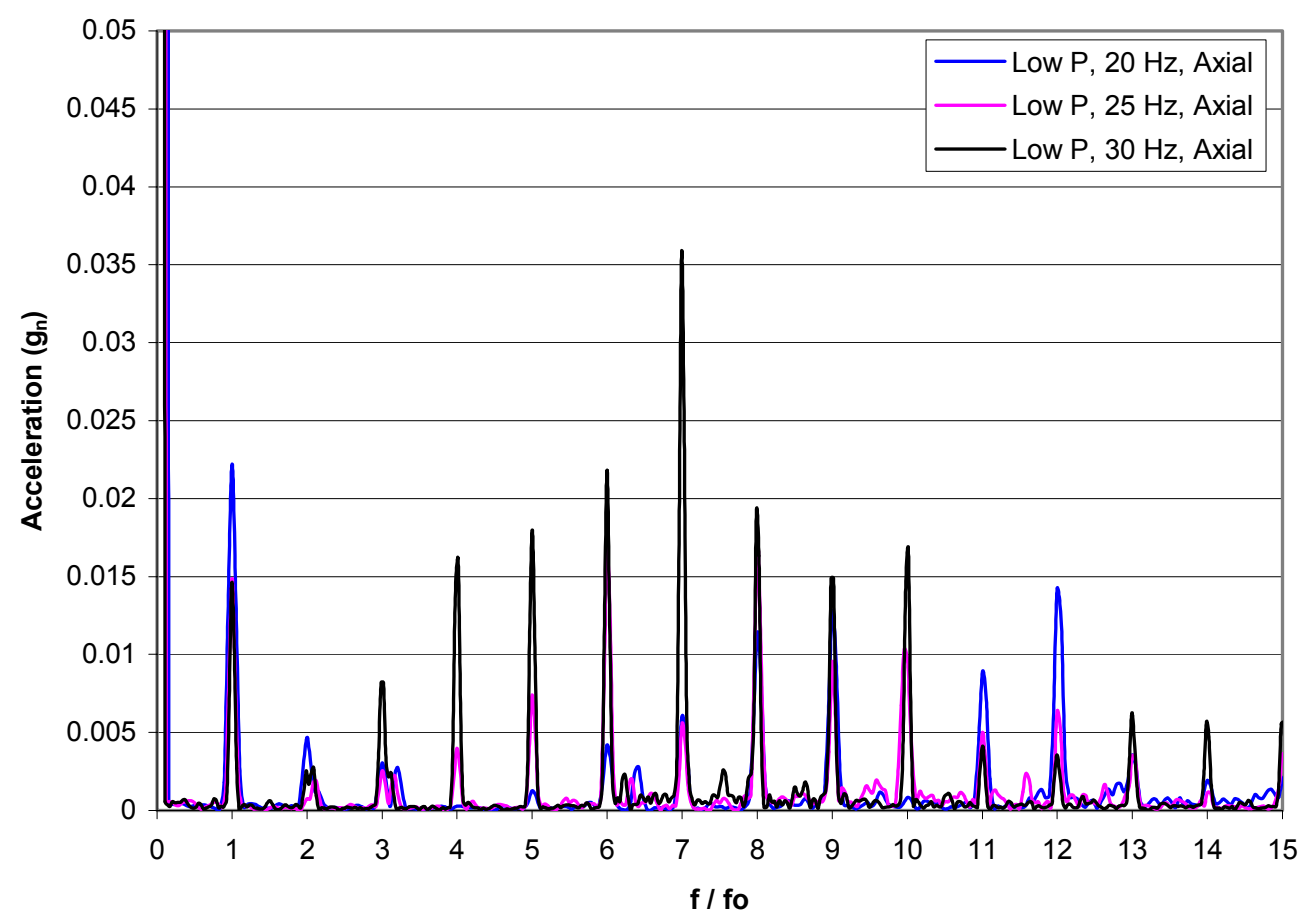

Figure 4.2.1: Axial acceleration for the scroll compressor at three frequencies at the low discharge pressure

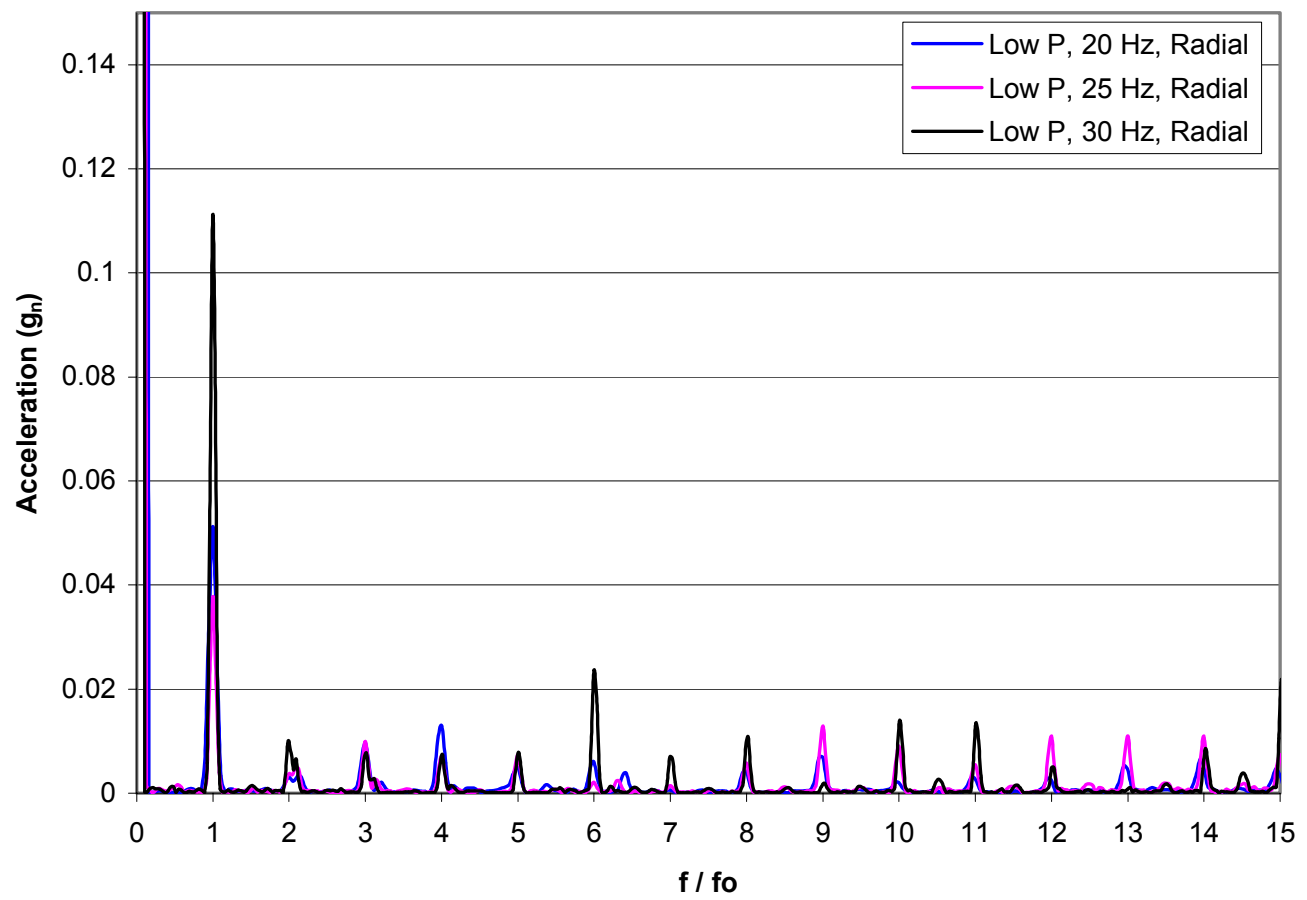

Figure 4.2.2: Radial acceleration for the scroll compressor at three frequencies at the low discharge pressure 


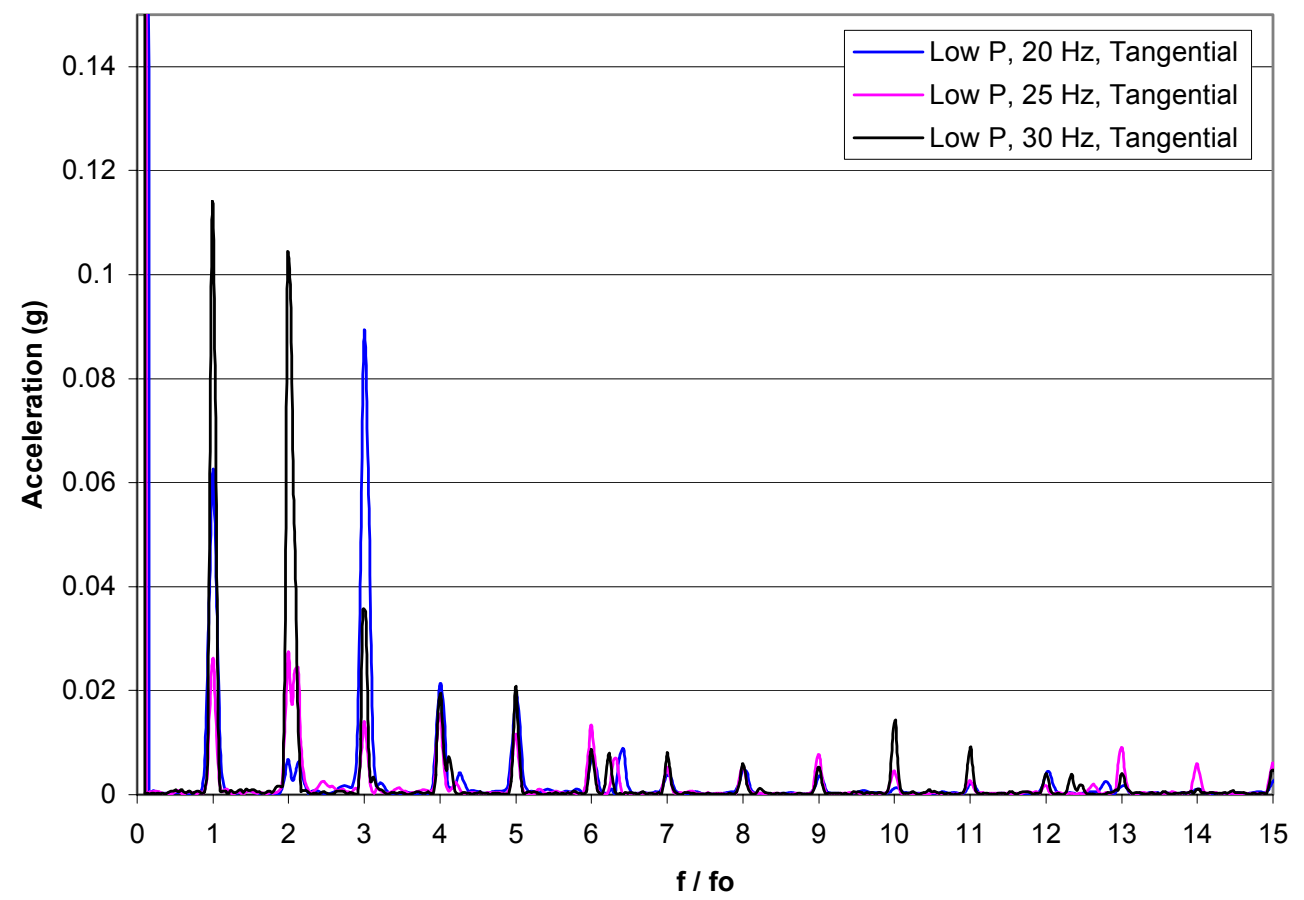

Figure 4.2.3: Tangential acceleration for the scroll compressor at three frequencies at the low discharge pressure

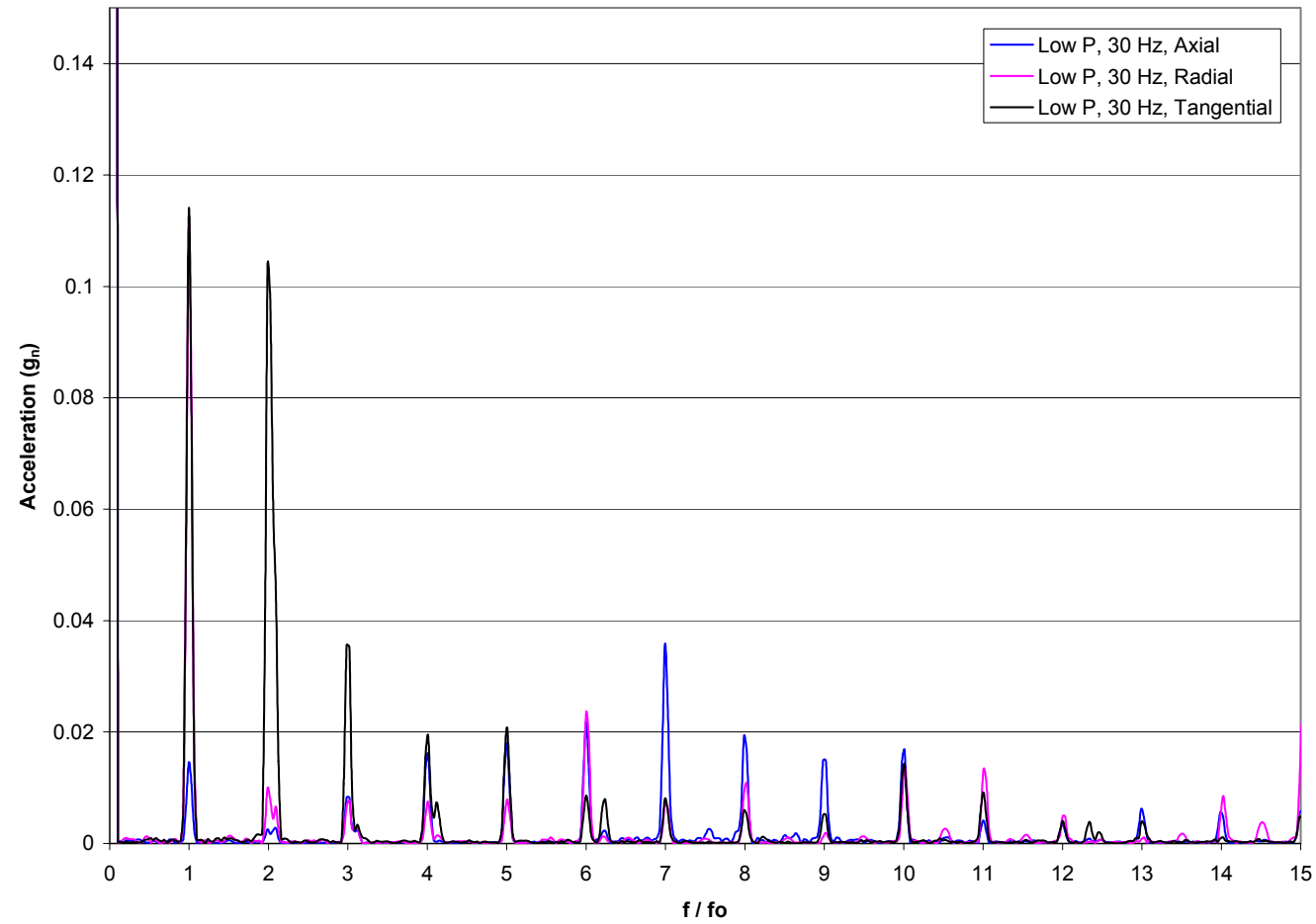

Figure 4.2.4: Axial, radial, tangential acceleration for the scroll compressor at $30 \mathrm{~Hz}$ at the low discharge pressure 


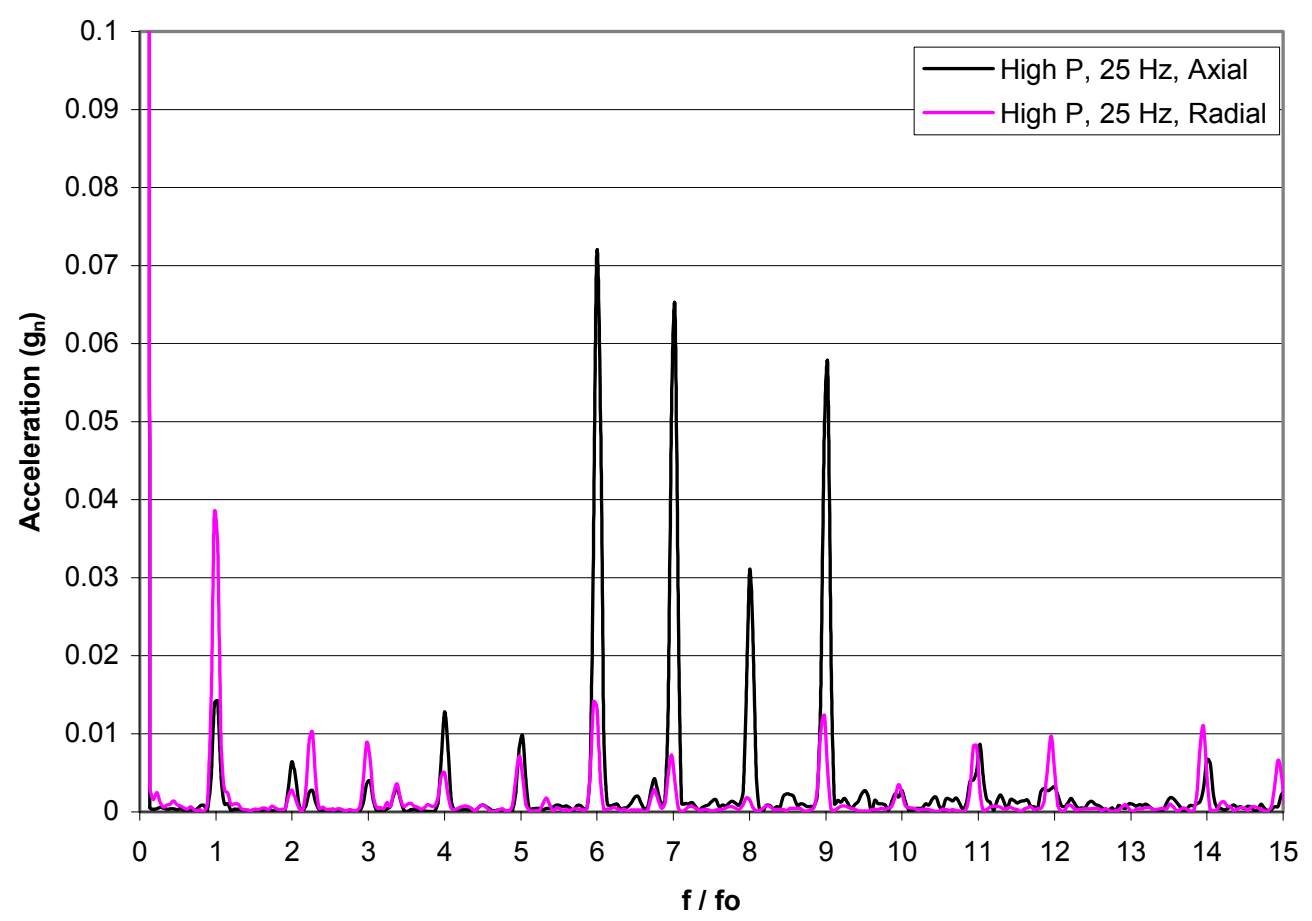

Figure 4.2.5: Axial and radial acceleration for the scroll compressor at $25 \mathrm{~Hz}$ at the high discharge pressure

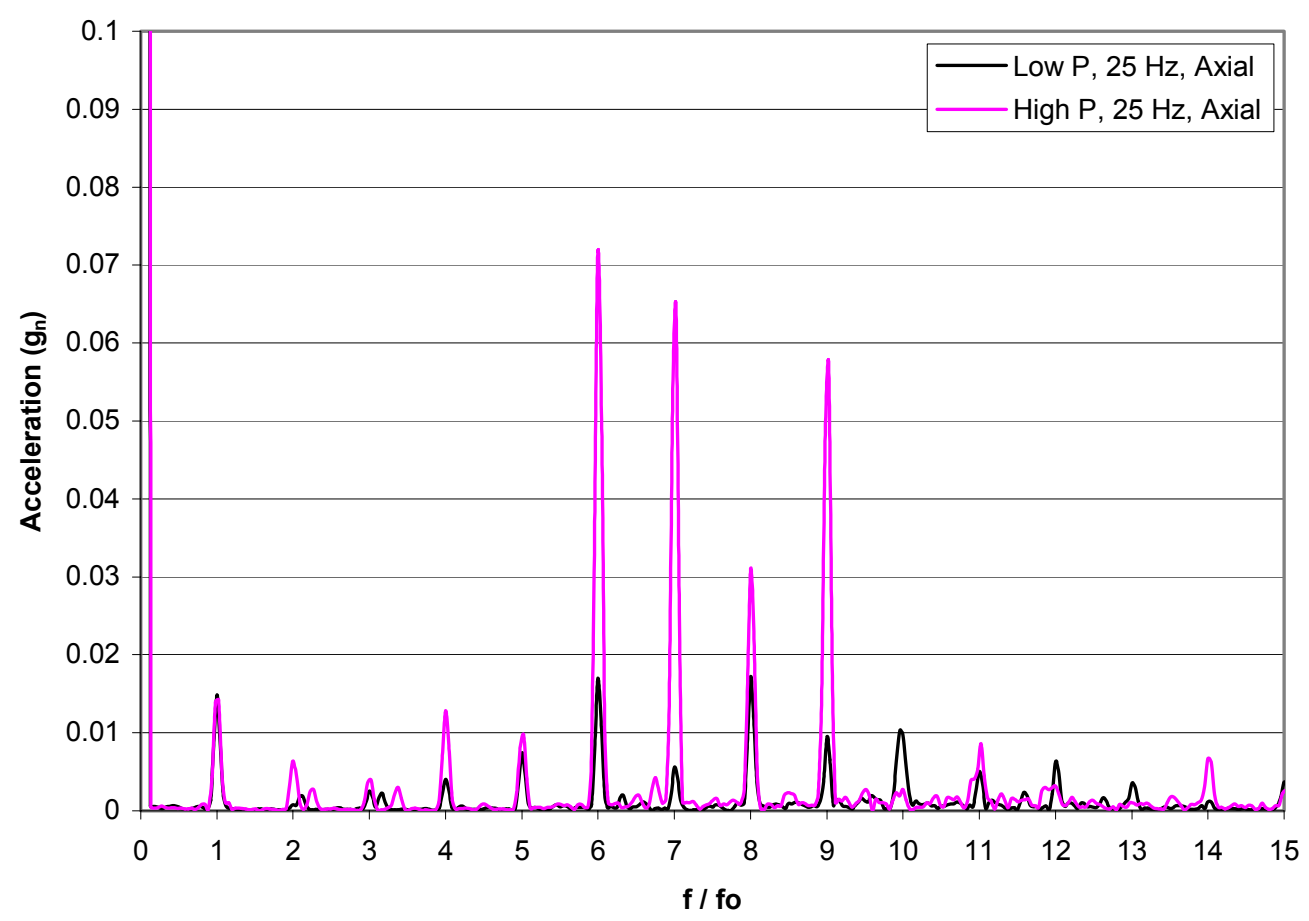

Figure 4.2.6: Radial acceleration for the scroll compressor at $25 \mathrm{~Hz}$ at the low and high discharge pressure 


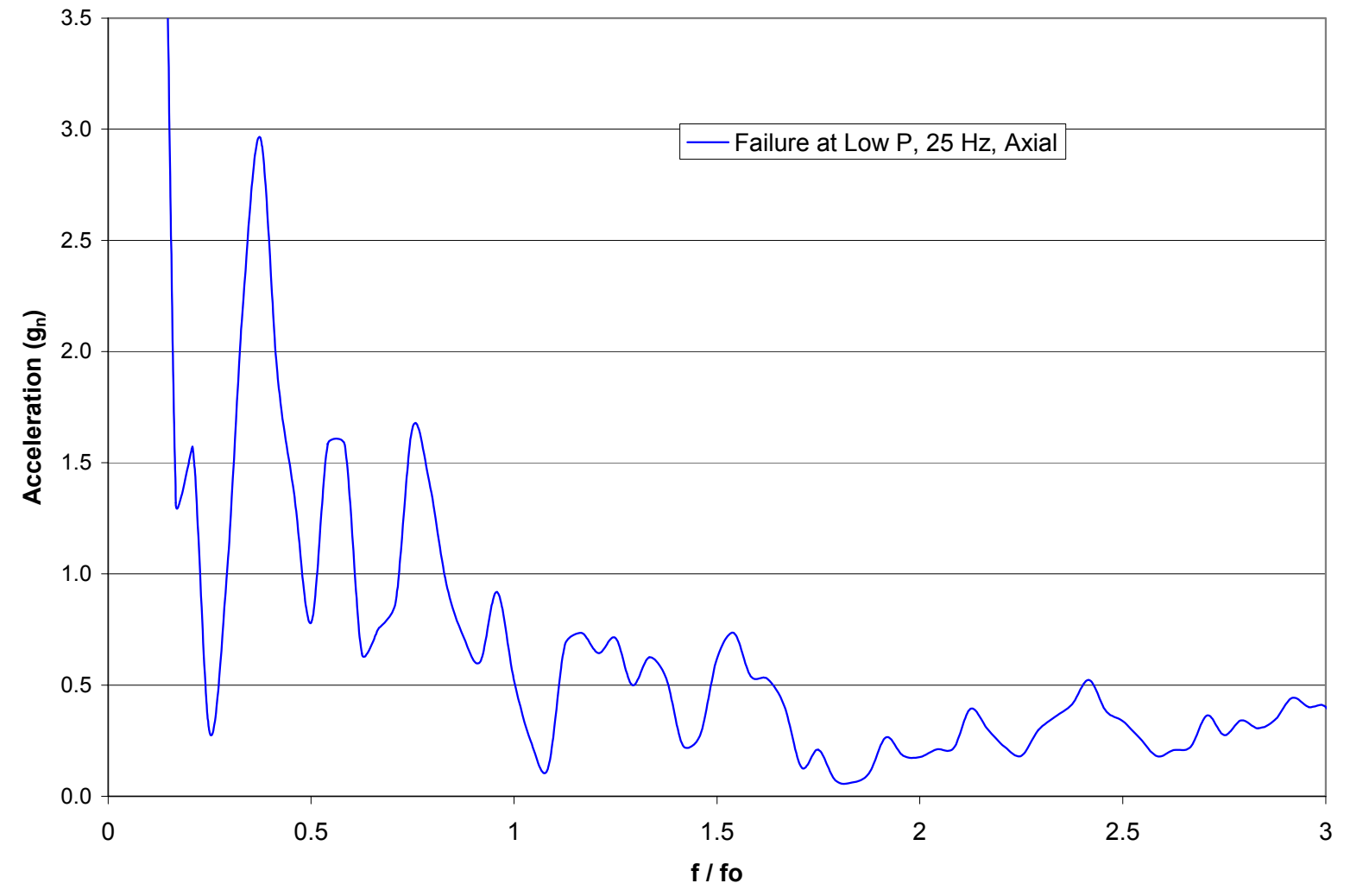

Figure 4.2.7: Axial acceleration for the scroll compressor failure at a drive frequency of $25 \mathrm{~Hz}$ and low pressure

\section{3: Six cylinder, reciprocating compressor vibration signatures}

The six cylinder reciprocating compressor was tested at three different levels of loading; operation with two, four, or six cylinders engaged. The figures below show the vibration amplitude with frequencies shown as multiples of the rotational frequency.

Figures 4.3.1, 4.3.2, and 4.3.3 show all three components of acceleration at multiples of the rotational speed for two-cylinder, four-cylinder, and six-cylinder operation, respectively. Figures 4.3.4, 4.3.5, and 4.3.5 show the axial, radial, and tangential components, respectively, of acceleration at multiples of the rotational speed for the three different loading levels. It is interesting to note that a $1 / 2 f_{0}$ component of acceleration was seen for each measurement, although this does not align with the shaft rotational frequency. This component is seen between the second and third harmonic, as well as multiples of $1 / 2 f_{0}$. Its magnitude was the smallest when the compressor was fully loaded and running on six cylinders. This $1 / 2 f_{0}$ component of vibration had the largest magnitude in the axial direction (parallel with the compressor crank shaft). No obvious reason for this vibration was noted, and it may be a normal phenomenon that was part of the compressor's no-fault vibration signature. 


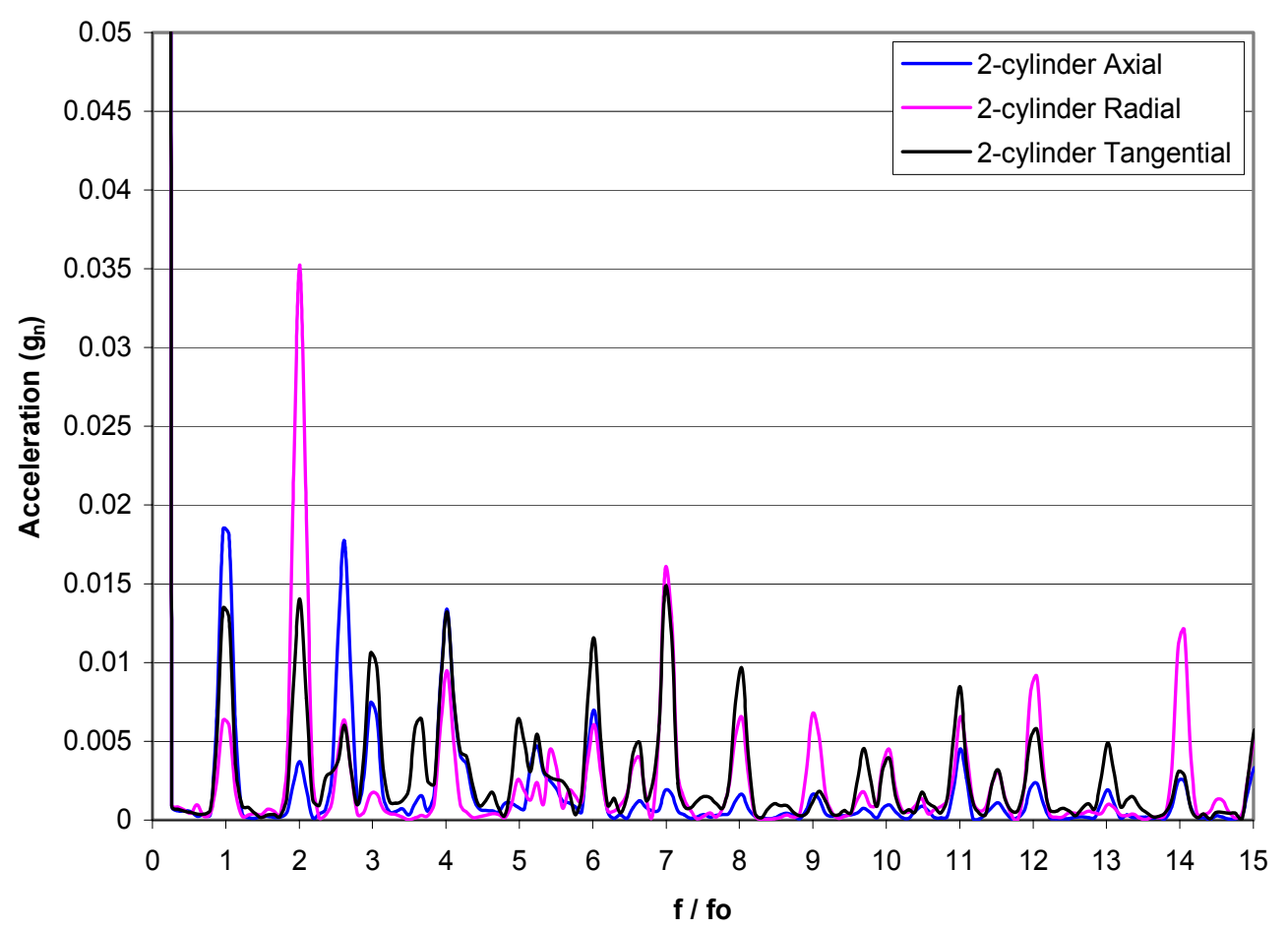

Figure 4.3.1: Axial, radial, and tangential acceleration with two cylinders loaded for the large reciprocating compressor

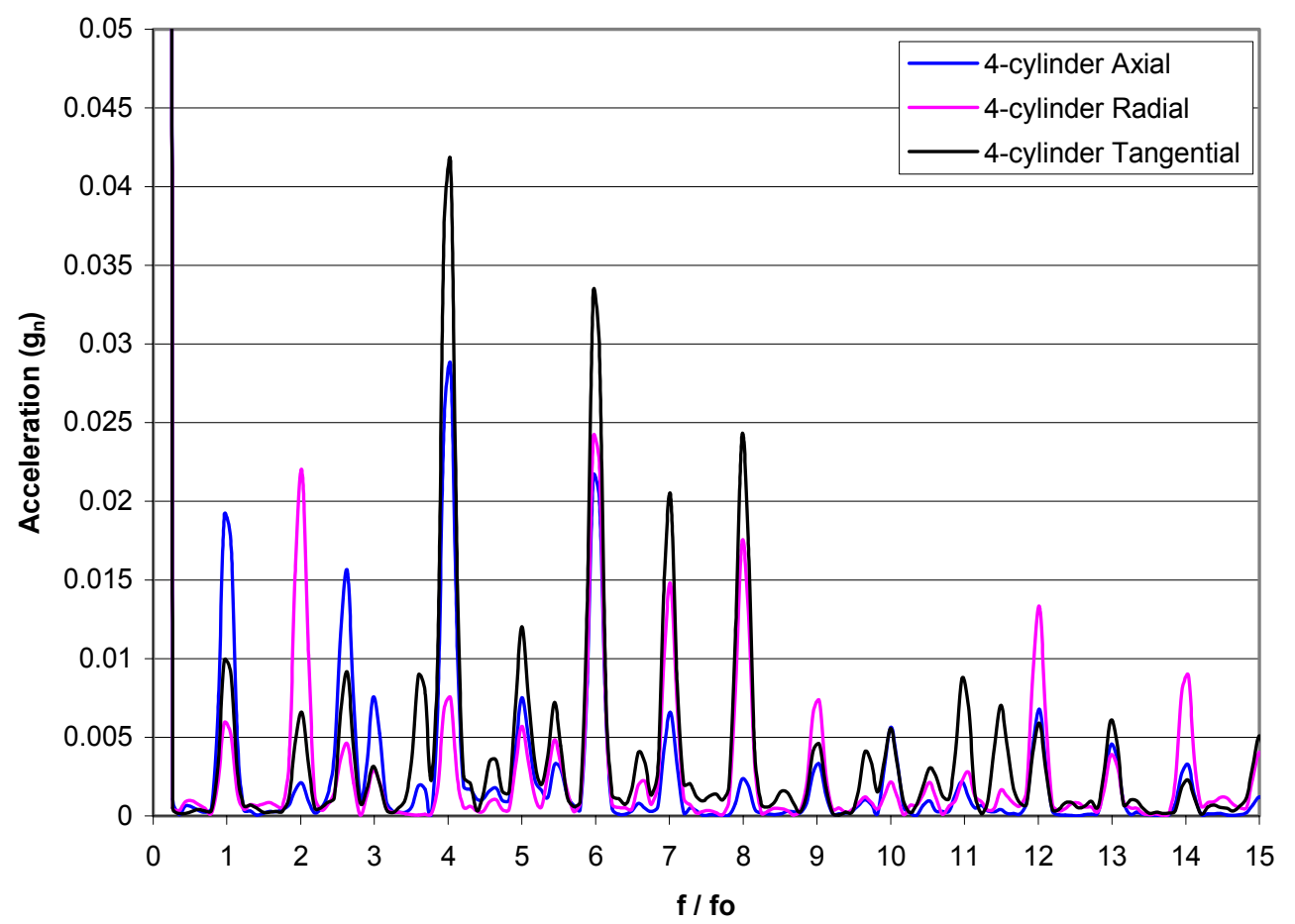

Figure 4.3.2: Axial, radial, and tangential acceleration with four cylinders loaded for the large reciprocating compressor 


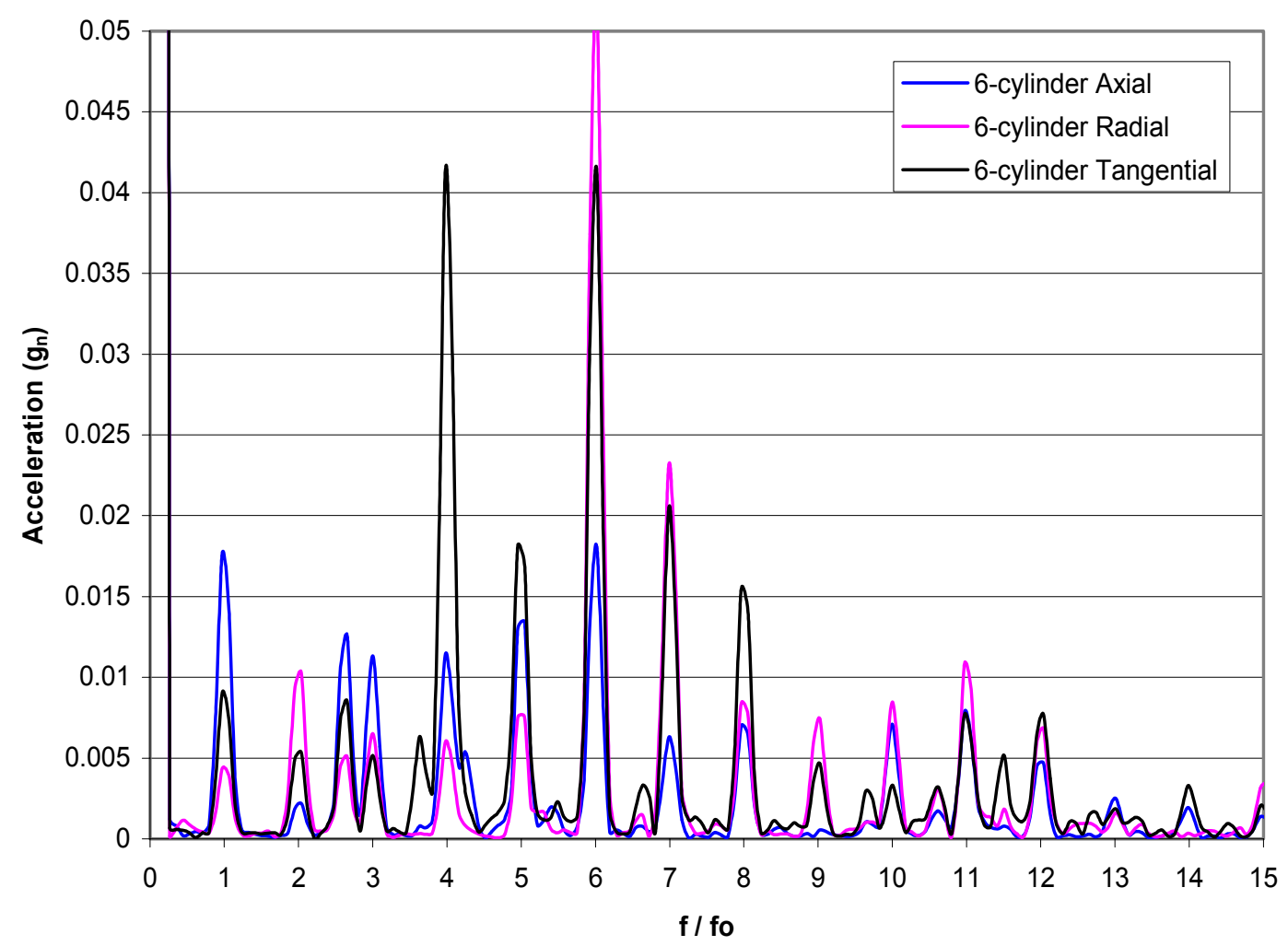

Figure 4.3.3: Axial, radial, and tangential acceleration with six cylinders loaded for the large reciprocating compressor

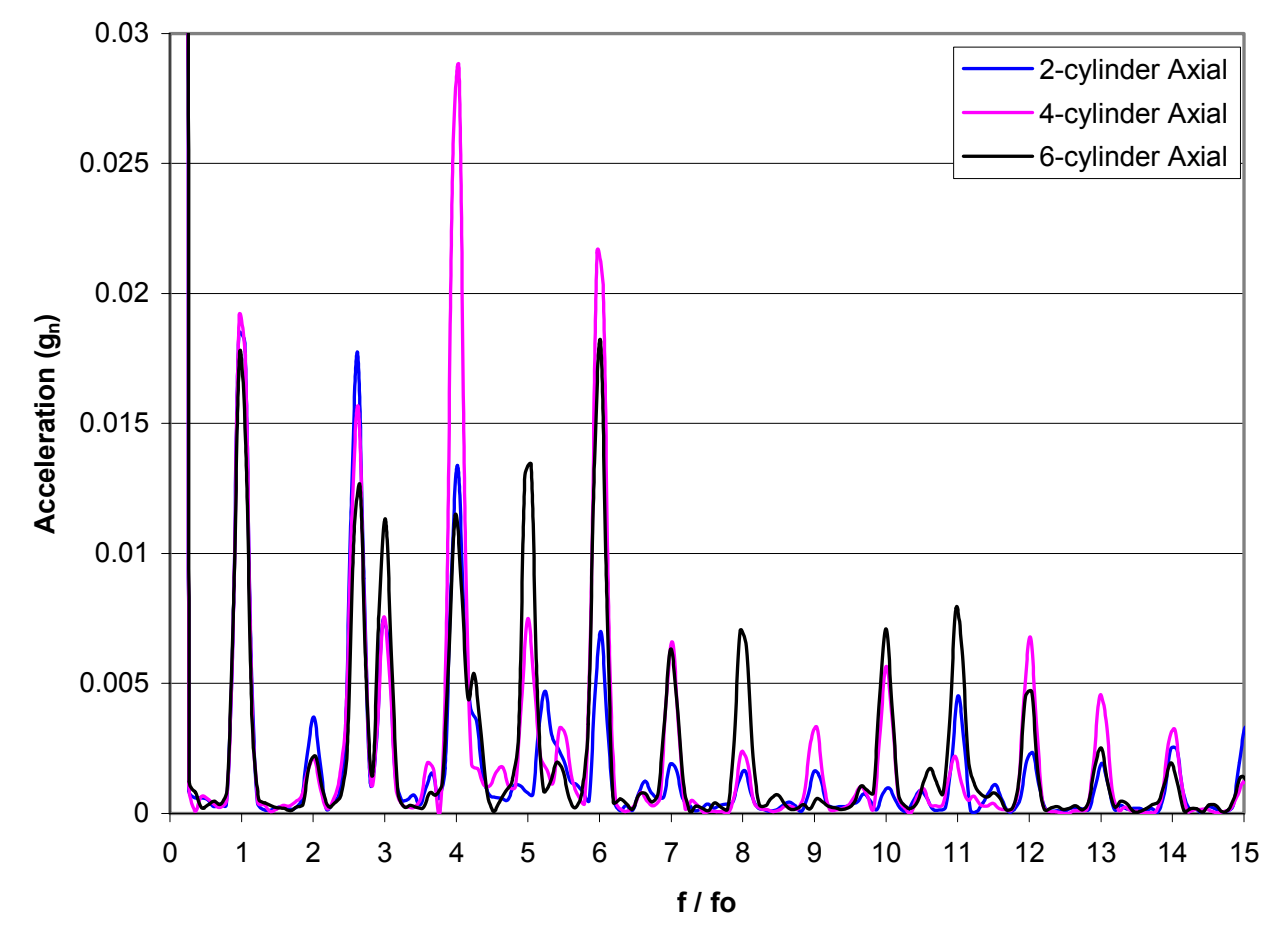

Figure 4.3.4: Axial acceleration with two, four, and six cylinders loaded for the large reciprocating compressor 


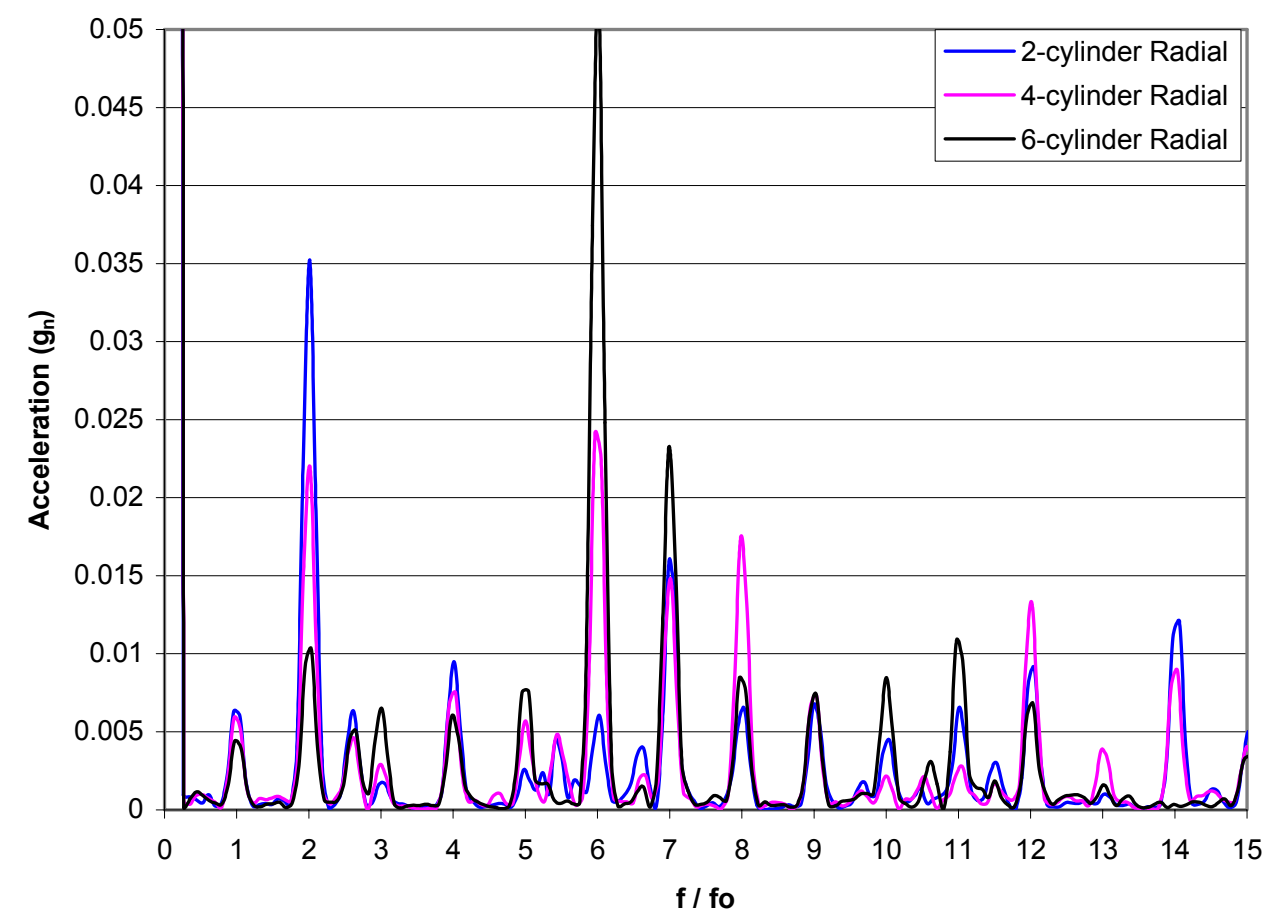

Figure 4.3.5: Radial acceleration with two, four, and six cylinders loaded for the large reciprocating compressor

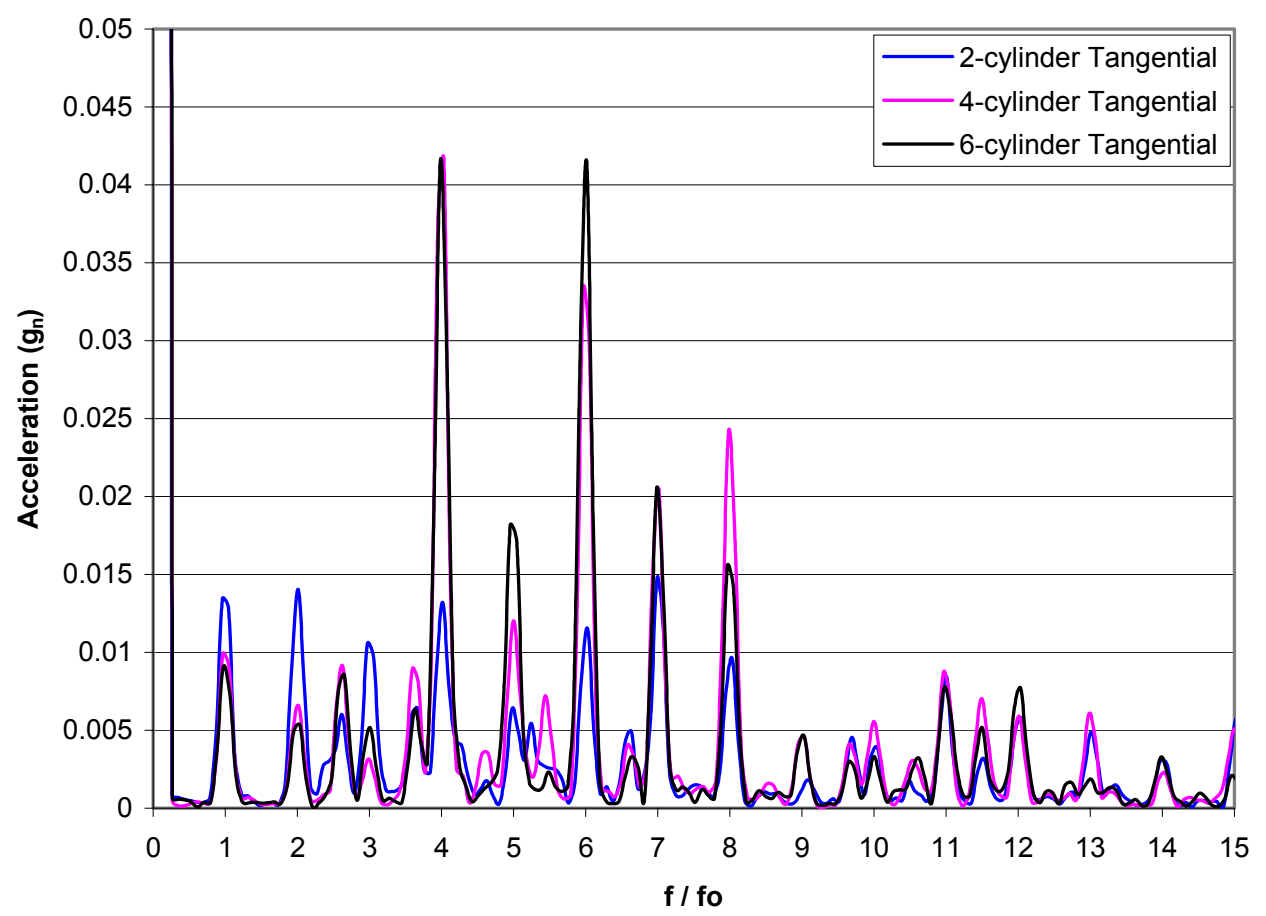

Figure 4.3.6: Tangential acceleration with two, four, and six cylinders loaded for the large reciprocating compressor 


\section{5: Concluding Remarks}

The preceding figures document the vibration characteristics of three different compressors. These vibration signatures are useful in evaluating a vibration meter that may be applied to future test systems; any vibration meter should have sampling and response characteristics sufficient to capture the vibrations seen with these compressors. The vibration signatures presented here are not meant to detect a fault within the compressor, but serve only to indicate the range of vibrations seen during normal operation of these compressors. Long term monitoring, trending, and fault simulations would need to be performed in order to diagnose a particular fault using vibration information. This document is intended to serve as a catalog for steady-state vibration information and help evaluation of future vibration measurement devices.

The vibration tests included a scroll compressor that had a failure during testing. This failure allowed characterization of the vibration amplitude and frequency that would be seen in an actual field-installed system. The vibration meter meant to detect this failure should have a resolution of at least $\pm 9.8 \mathrm{~m} / \mathrm{s}^{2}\left( \pm 1 \mathrm{~g}_{\mathrm{n}}\right)$. Normal operations of all the compressors tested here were below $4.9 \mathrm{~m} / \mathrm{s}^{2}\left(0.5 \mathrm{~g}_{\mathrm{n}}\right)$ in all directions. Vibration meters with greater sensitivity may cost more to produce and may be less robust in a compressor system environment. At a minimum, all of these factors must be weighed against development and economic constraints when designing a workable vibration meter. 


\section{References}

Johnson, Michael S. "Vibration Tests for Bearing Wear," ASHRAE Journal, October 2000, pp. $52-58$. 


\section{Appendix A: Vibration Analysis Derivations for Rolling Element Bearings}

Figure A.1 shows a schematic of a rolling element bearing. The inner race has a radius $\mathrm{R}$, the roller has a radius $r$, and the shaft is rotating clockwise at a rate $\omega_{\mathrm{s}}$. The position of the roller relative to the center of the shaft is defined by the angle $\phi$. There are $n$ rollers distributed throughout the bearing.

Because the top of the roller is in contact with the fixed outer race, and the bottom of the roller is in contact with the inner race at point $\mathrm{A}$, the velocity of point $\mathrm{A}$ is defined by:

$V_{A}=2 r \times \dot{\theta}$

$\theta$ defines the angle of rotation of the roller.

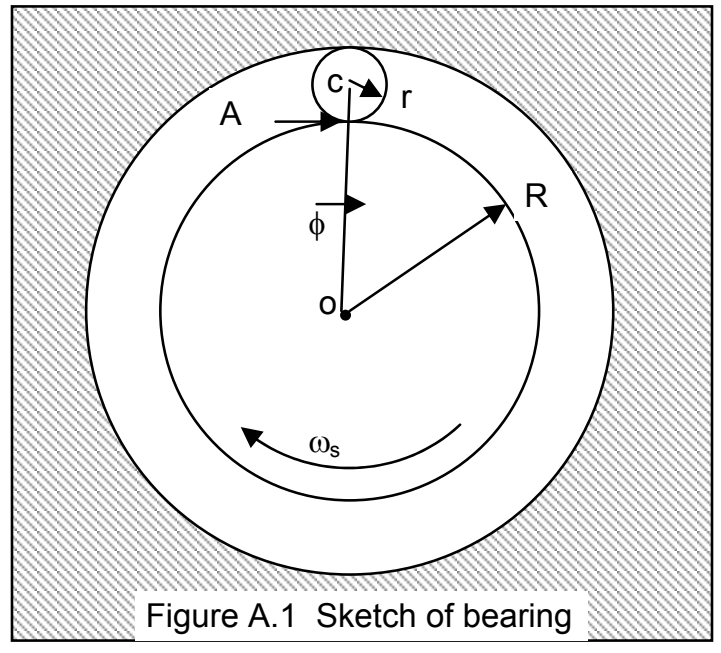

The velocity of this point is also defined by its position relative to the center of the shaft: $V_{A}=-R \times \omega_{S}$

Therefore, the angular rate of rotation of the roller is related to the shaft rotation rate:

$\dot{\theta}=-\frac{R}{2 r} \omega_{s}$

The velocity of the center of the roller is defined by its path around the center of the shaft:

$V_{c}=-(R+r) \times \dot{\phi}$

But since the top of the roller is the instantaneous center of rotation, the velocity of point $\mathrm{C}$ is also defined by:

$V_{c}=r \times \dot{\theta}$

Therefore the rate at which the roller orbits the center of the shaft is related to the rotation rate of the roller:

$$
\dot{\phi}=-\frac{r}{(R+r)} \times \dot{\theta}
$$

And therefore, it is related to the shaft rotation rate:

$$
\dot{\phi}=\left(-\frac{r}{(R+r)}\right) \times\left(-\frac{R}{2 r} \omega_{s}\right)=\frac{R}{2(R+r)} \omega_{s}
$$

This is the rate at which a fixed point on the outer race of the bearing will be in contact with a roller. If a defect were present on the surface of the outer race, it would be impacted by the 
roller at this rate. Since there are $\mathrm{n}$ rollers evenly spaced along this bearing, the rate at which rollers come into contact with this defect is related to the shaft rotation rate:

$\omega_{\text {outer, contact }}=\frac{n R}{2(R+r)} \omega_{s}$

The rate of contact between an inner race surface defect and a roller is found as follows. The angle of rotation of the shaft, $\alpha\left(\omega_{\mathrm{s}}\right.$ is the time derivative of $\left.\alpha\right)$, is related to the orbital rate of the roller. From the previous step:

$$
\frac{d \phi}{d t}=\frac{R}{2(R+r)} \frac{d \alpha}{d t}
$$

The roller will be in contact with the same point on the inner race every time the inner race laps the roller:

$\phi=\alpha-2 k \pi$

Therefore:

$$
\begin{aligned}
& \phi=\alpha-2 k \pi=\frac{R}{2(R+r)} \alpha \\
& 2 k \pi=\left(1-\frac{R}{2(R+r)}\right) \alpha=\frac{(R+2 r)}{2(R+r)} \alpha
\end{aligned}
$$

Since there are $\mathrm{n}$ rollers, the rate at which rollers come into contact with a point on the inner race is:

$$
\omega_{\text {inner }, \text { contact }}=\frac{n(R+2 r)}{2(R+r)} \omega_{s}
$$

Finally, in order to find the impact rate for a defect on the surface of a roller itself, one must visualize the roller completing one full orbit:

$$
\phi=2 \pi
$$

During this orbit, the prior relationship shows that the roller will rotate through an angle of:

$$
\theta=\frac{2 \pi}{r}(R+r)
$$

In other words, the roller will go through $\frac{(R+r)}{r}$ rotations as it completes one orbit.

Since one contact with each race is added through each orbit because of the changing angle of contact, a point on the surface of the roller will be in contact $\frac{(R+2 r)}{r}$ times with each race. 
Since there are an inner and an outer race, this point will be impacted a total

$$
\frac{2(R+2 r)}{r} \text { times throughout each orbit. }
$$

Since the orbital rate is related to the shaft rotation rate:

$$
\dot{\phi}=\frac{R}{2(R+r)} \omega_{s}
$$

A point on the surface of a roller will be in contact with the races at the rate of:

$$
\omega_{\text {roller, }, \text { impact }}=\frac{R(R+2 r)}{r(R+r)} \omega_{s}
$$

